\title{
¿Impacts of Tibetan Plateau Snow Cover on the Interannual Variability of the East Asian Summer Monsoon $\mathscr{A}$
}

\author{
ZHIXIANG XIAO \\ State Key Laboratory of Numerical Modeling for Atmospheric Sciences and Geophysical Fluid Dynamics, \\ Institute of Atmospheric Physics, Chinese Academy of Sciences, Beijing, and Guangxi \\ Meteorological Observatory, Nanning, China \\ ANMIN DUAN \\ State Key Laboratory of Numerical Modeling for Atmospheric Sciences and Geophysical Fluid Dynamics, \\ Institute of Atmospheric Physics, Chinese Academy of Sciences, Beijing, and Collaborative Innovation \\ Center on Forecast and Evaluation of Meteorological Disasters, Nanjing University of \\ Information Science and Technology, Nanjing, China
}

(Manuscript received 28 December 2015, in final form 18 August 2016)

\begin{abstract}
The relationship between Tibetan Plateau (TP) snow cover and the East Asian summer monsoon (EASM) has long been discussed, but the underlying mechanism remains controversial. In this paper, the snow-albedo and snow-hydrology feedbacks over the TP are investigated based on multiple sources of snow data for the period 1979-2011. The results indicate that winter snow cover plays an important role in cooling local air temperature through the snow-albedo effect; the TP surface net solar radiation in years with above-normal snow cover is approximately $18 \mathrm{~W} \mathrm{~m}^{-2}$ less than that in below-normal snow cover years. However, data analysis demonstrates that persistent effects of winter snow cover are limited to the period from winter to spring over most parts of the central and eastern TP. Therefore, the preceding snow cover over the central and eastern TP exerts little influence over either the in situ summer atmospheric heat source or the EASM, because of its limited persistence. In contrast, the effects of winter or spring snow cover anomalies over the western TP and the Himalayas can last until summer, and these anomalies further influence the EASM by modulating moisture transport to eastern China and favoring eastward-propagating synoptic disturbances that are generated over the TP. Generally, above-normal snow cover over the western TP and the Himalayas facilitates abundant summer precipitation between the Yangtze and Yellow River basins, which is confirmed by results from a regional Weather Research and Forecasting model simulation.
\end{abstract}

\section{Introduction}

Snow cover exerts a significant influence on local surface radiation budgets and hydrological fluxes through its high reflectivity, high emissivity, and low thermal conductivity

๑ Denotes Open Access content.

Supplemental information related to this paper is available at the Journals Online website: http://dx.doi.org/10.1175/ JCLI-D-16-0029.s1.

Corresponding author address: Dr. Anmin Duan, LASG, Institute of Atmospheric Physics, Chinese Academy of Sciences, P.O. Box 9804, Beijing 100029, China.

E-mail: amduan@lasg.iap.ac.cn
(Yasunari et al. 1991; Mote 2008; Xu and Dirmeyer 2013). However, in addition to local effects, snow cover might also impact downstream climate systems (Xu et al. 2012) and the global climate (Barnett et al. 1988, 1989).

Eurasian snow cover has long been thought to significantly influence the Asian summer monsoon. More than a century ago, Blanford (1884) and Walker (1910) found a negative relationship between the winter snow cover over the Himalayas and the subsequent rainfall during the Indian summer monsoon, and Hahn and Shukla (1976) were the first to use satellite-derived Eurasian snow cover data to verify the relationship found by Blanford (1884). Later, using snow cover data from meteorological stations, Chen

This article is licensed under a Creative Commons Attribution 4.0 license. 
and Yan (1979) concluded that the winter-spring snow cover of the Tibetan Plateau (TP) may be an important predictor of rainfall in southern China during the pre-rainy period. Similarly, many studies (e.g., Yasunari et al. 1991; Ose 1996; Bamzai and Shukla 1999; Chen and Wu 2000; Wu and Qian 2003; Zhao et al. 2007; Liu et al. 2014a,b) have focused on the relationship between TP snow cover and the East Asian summer monsoon (EASM), and some potential mechanisms for the impact of snow cover on the EASM have been proposed. Chen et al. (2000) found that above-normal TP winter snow cover may trigger El Niño events and weaken the subsequent summer monsoon, leading to more rainfall over the middle and lower reaches of the Yangtze River valley. Zhang and Tao (2001) argued that more snow cover over the TP will weaken the sensible heat of the surface and the lower tropospheric temperature surrounding the TP. This will reduce the tropospheric land-sea temperature contrast and weaken the EASM, which will lead to summer flooding of the Yangtze River. More recently, Y. S. Zhang et al. (2004) suggested that snowmelt over the TP can cool surface temperatures and provide sufficient moisture for the development of eastward-migrating low-level vortices. Liu et al. (2014a) found that excessive summer snow cover over the western TP suppresses local vertical motion and, consequently, benefits upward motion over the north Indian Ocean via a meridional vertical circulation system, which is favorable for the occurrence of precipitation. A Kelvin wave-type response over the tropics then takes place, inducing easterly wind anomalies, and, through a zonal circulation system, sinks over the western Pacific warm pool. The suppressed convective activity in the western Pacific stimulates the East Asia-Pacific teleconnection pattern and affects the mei-yu rain belt. Thus, two aspects of the effect of TP snow cover on the EASM can be considered: the local effect of snow cover, in which excessive snow cover may weaken surface heating, prolonged by the snowhydrology effect (Yasunari et al. 1991; Zhang and Tao 2001; Qian et al. 2003; Y. S. Zhang et al. 2004; Zhu et al. 2009); and the interaction between snow cover and the tropical atmosphere (Chen et al. 2000; Liu et al. 2014a).

Despite many potential mechanisms for the effect of snow cover on the EASM having been proposed, a number of studies have maintained that Eurasian snow cover has a limited influence on subsequent atmospheric circulation. Cohen and Rind (1991) argued that snow cover causes only a short-term decrease in local surface temperature, due to negative feedbacks in the surface energy budget; the surface air temperature anomalies induced during the snow disappearance period will diminish in May (Ueda et al. 2003). Over the vast Eurasian continent, the snow-hydrology effect on summer precipitation has mainly been detected over the west Siberian plain (Wu et al. 2014), where soil moisture anomalies persist for more than three months. Based on global climate model results, Zwiers (1993) found the TP spring snowpack to be only weakly connected to the subsequent Asian summer monsoon. Because of its limited persistence, winter snow cover cannot physically control the summer monsoon because the impact of anomalous snow cover on temperature cannot be prolonged by soil moisture feedbacks (Robock et al. 2003). To a certain degree, the contrasting results obtained by different authors are due to the large uncertainties in snow cover datasets.

Snow cover mainly affects the atmosphere through the snow-albedo effect and the snow-hydrology effect (Hahn and Shukla 1976; Yeh et al. 1983; Yasunari et al. 1991; Souma and Wang 2010). Previous studies have emphasized a robust relationship between winter TP snow cover and the EASM, and have attempted to illustrate the potential mechanism involved in summer (Chen et al. 2000; Zhang and Tao 2001; Y. S. Zhang et al. 2004; Xu et al. 2012). However, research of this nature has rarely focused on the evolution of albedo and soil moisture from winter to summer under different TP snow cover conditions. Therefore, we still do not know whether the snow-albedo and snow-hydrology effects continue to significantly influence general circulation in summer, especially over the central and eastern TP. Based on meteorological station data, winter snow cover in this region correlates significantly with the EASM (Chen and Wu 2000; Chen et al. 2000; Zhang and Tao 2001; Xu et al. 2012), but the in situ snow cover is much less than that in the western TP and the Himalayas.

In this study, we ask the following: Can winter and spring snow cover anomalies over the TP influence the interannual variability of the EASM? If so, which parts of the TP are responsible? And what is the intrinsic physical mechanism responsible for such a delayed impact? We answer these questions through data analysis, and verify the findings via a model simulation, reported as follows: in section 2, the data and methodology are described; section 3 presents the snow-albedo and snow-hydrology effects over the central and eastern TP; section 4 discusses the impacts of snow cover over the western TP and Himalayas on the EASM; the model results are examined in section 5; and a summary and discussion conclude the paper in section 6 .

\section{Data and methodology}

\section{a. Data}

The data used in this work include the following:

1) Daily surface-observed snow depth, precipitation, ground surface temperature, depth of the upper 

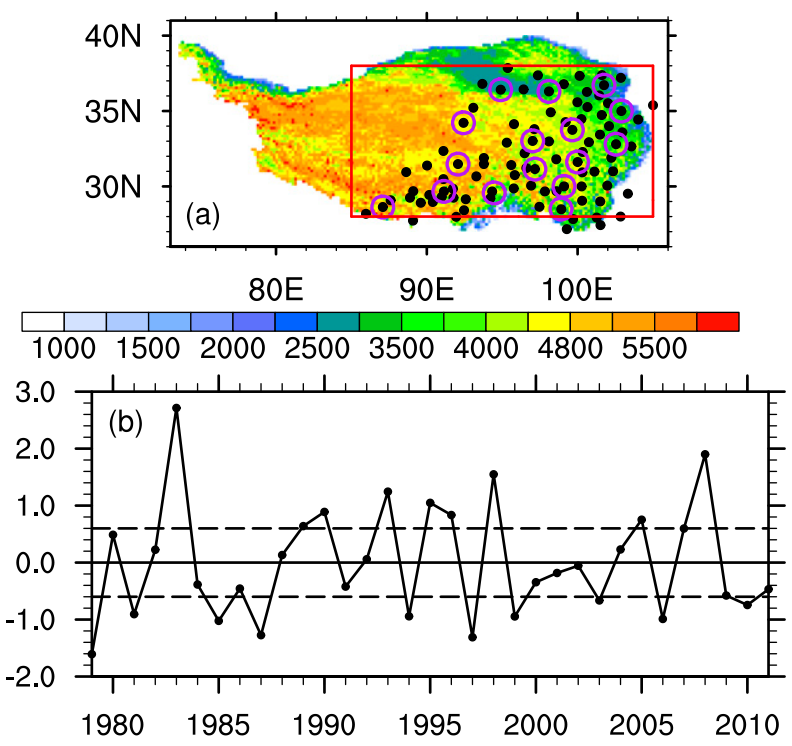

FIG. 1. (a) Spatial distribution of 92 surface meteorological stations (black dots) including 16 radiosonde stations (purple open circles), across the TP. The red rectangle represents the central and eastern TP $\left(28^{\circ}-38^{\circ} \mathrm{N}, 85^{\circ}-105^{\circ} \mathrm{E}\right)$. The colored shading denotes topography $\geq$ $1000 \mathrm{~m}$ above sea level. (b) Time series of the standardized winter NSCD index, averaged across the 92 stations (Fig. 1a, black dots) over the TP from 1979 to 2011 with the linear trend removed. The dashed lines indicate \pm 0.6 standard deviations.

frozen soil boundary, and the number of snow cover days (NSCDs), during 1979-2011, collected from 756 meteorological stations across China, 92 of which are situated in the central and eastern TP (Fig. 1a, black dots), provided by the China Meteorological Administration (CMA). Monthly air temperature records from 16 radiosonde stations over the central and eastern TP (Fig. 1a, open circles), for the same period (1979-2011), again from the CMA, are also used. There are 12 standard pressure levels $(500,400$, $300,250,200,150,100,70,50,30,20$, and $10 \mathrm{hPa}$ ). Following Duan and Wu (2008), the atmospheric heat source-sink over the central and eastern TP is defined as the arithmetic sum of the surface sensible heat flux (calculated by the bulk aerodynamic method), the latent heat released to the atmosphere by condensation, and the air column net radiation flux [based on the station and satellite radiation dataset GEWEX SRB (i.e., surface radiation budget; Stackhouse et al. 2004)]. All fluxes in this paper are defined as positive in the downward direction.

2) Satellite-derived snow depth data, obtained from the U.S. National Snow and Ice Data Center (NSIDC; http://nsidc.org/), based on measurements by the Scanning Multichannel Microwave Radiometer (SMMR; 1979-87), the Special Sensor Microwave Imager (SSM/I; 1987-2008), and the Advanced
Microwave Scanning Radiometer-Earth Observing System (AMSR-E; 2002-10). Using an improved algorithm for China, Dai and Che (2010) determined snow depths at a spatial resolution of $0.25^{\circ} \times 0.25^{\circ}$ during 1979-2011. In addition, the monthly satellitederived snow water equivalent (SWE) data for the period 1979-2006, derived from SMMR and SSM/I (Armstrong et al. 2005), and weekly snow cover data for 1967-2011, obtained from NSIDC, are also used. The NSIDC SWE and snow cover data are gridded to $25-\mathrm{km}$ equal-area scalable Earth grids. Last, monthly snow cover data, for the period 1967-2013, collected from $89 \times 89$ grid points over the Northern Hemisphere, obtained from the Rutgers University Global Snow Laboratory (http://climate.rutgers.edu/snowcover/), are used. For convenience, the SWE and snow cover data are regridded to regular $0.25^{\circ} \times 0.25^{\circ}$ grid for analysis.

3) Three monthly satellite radiation products: (i) GEWEX SRB (Stackhouse et al. 2004), version 3.0, for the period 1984-2007, with a spatial resolution of $1^{\circ} \times$ $1^{\circ}$; (ii) ISCCP-D2 (Y. C. Zhang et al. 2004), for the period 1984-2009, with a spatial resolution of $2.5^{\circ} \times$ $2.5^{\circ}$; and (iii) CERES (Wielicki et al. 1996), starting from 2000 , with a spatial resolution of $1^{\circ} \times 1^{\circ}$.

4) Monthly mean atmospheric variables, for the period 1979-2011, including winds, surface pressure, specific humidity, and temperature, from the European Centre for Medium-Range Weather Forecasts interim reanalysis (ERA-Interim; Dee et al. 2011), all on regular $1.5^{\circ} \times 1.5^{\circ}$ grid. Note that similar results were obtained from the Japanese 55-year Reanalysis (Ebita et al. 2011). Also used are the surface evapotranspiration and $0-10-\mathrm{cm}$ soil moisture data from the Noah land surface model from Global Land Data Assimilation System version 2 (GLDAS-2) products (Rodell et al. 2004); the data are available as $1^{\circ} \times 1^{\circ}$ grid starting from 1948.

5) Monthly precipitation datasets, including the Asian Precipitation-Highly Resolved Observational Data Integration Toward Evaluation of Water Resources (APHRODITE; http://www.chikyu.ac.jp/precip/), and the gauge-based APHRODITE (MA V1101) gridded $\left(0.25^{\circ} \times 0.25^{\circ}\right)$ precipitation dataset, which spans the period 1951-2007 and covers most parts of the Asian land surface. The combined global monthly mean precipitation datasets of the Climate Prediction Center (CPC) Merged Analysis of Precipitation (CMAP; Xie and Arkin 1997) and the Global Precipitation Climatology Project (GPCP V2.2; Adler et al. 2003) are used, both of which are available on $2.5^{\circ} \times 2.5^{\circ}$ grid starting from January 1979. 

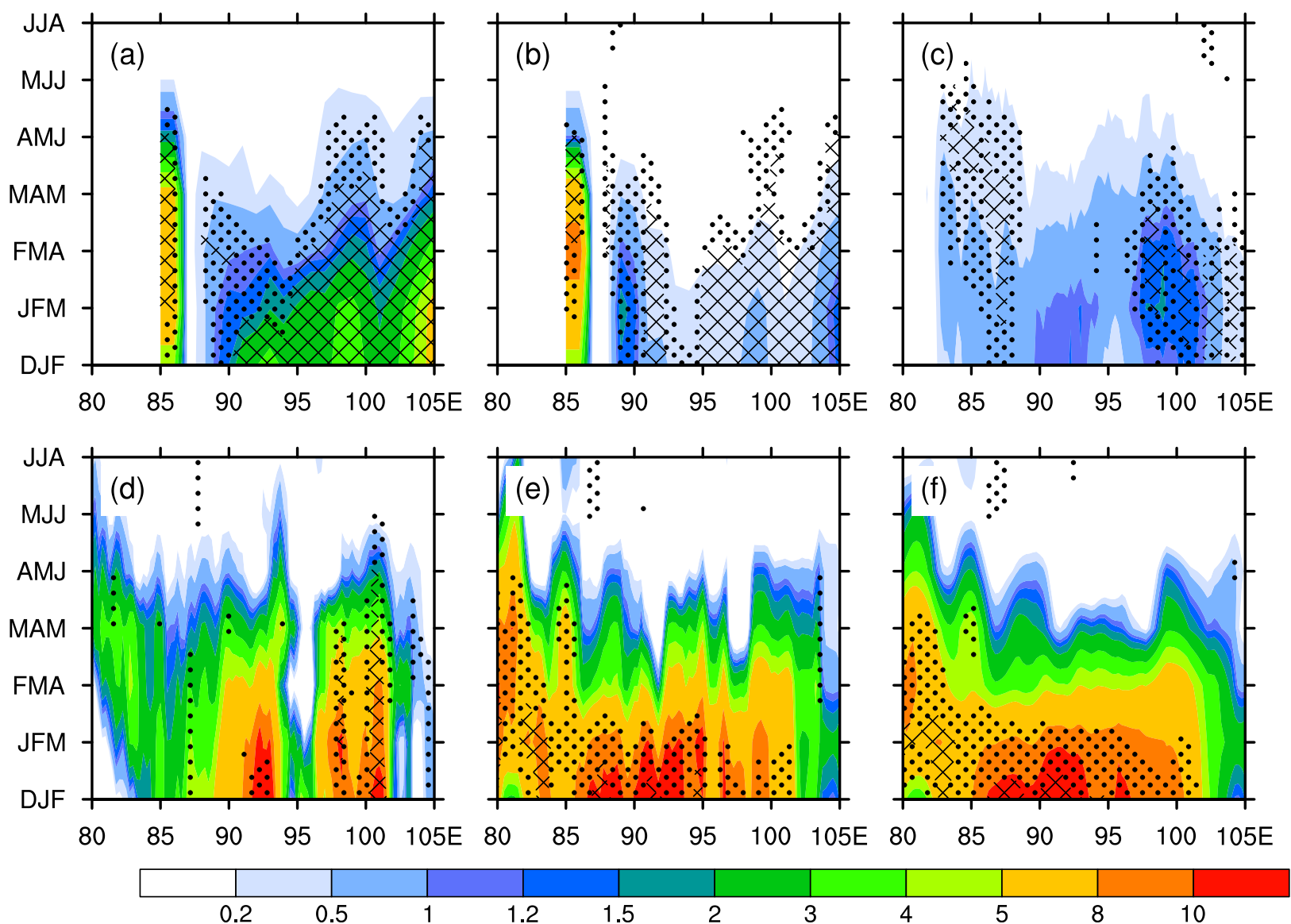

FIG. 2. Longitude vs 3-month (in seven categories from DJF through JJA) differences of snow datasets between above- and belownormal snow cover years, based on the winter NSCD index averaged from $28^{\circ}$ to $38^{\circ} \mathrm{N}$ : (a) station-observed NSCDs (days), (b) stationobserved snow depth $(\mathrm{cm})$, (c) satellite-derived snow depth $(\mathrm{cm})$ improved by Dai and Che (2010), (d) satellite-derived SWE (mm) obtained from NSIDC, (e) satellite-derived snow cover (\%) obtained from NSIDC, and (f) satellite-derived snow cover (\%) obtained from Rutgers University. The dotted (cross-hatched) regions indicate statistical significance at the $90 \%$ (95\%) confidence level according to the Student's $t$ test; this convention is also used in subsequent figures.

\section{b. Methodology}

Because this study focuses on interannual variability, linear trends are removed from all of the time series; we then subtract the 9-yr running average from the trendremoved series, following the method of Qian et al. (2011). This method is convenient as it involves less computation, and the results are almost the same as those from harmonic analysis.

El Niño-Southern Oscillation (ENSO) exerts a substantial impact of the EASM (e.g., Wang et al. 2000; Huang et al. 2004). Therefore, when considering whether TP snow cover has an impact on the EASM in section 4, the ENSO signal must be removed. Following Gong et al. (2011), we remove the ENSO signal by means of regression analysis. The climate variables are regressed onto the Niño-3 index (averaged from the preceding December-May), and a new time series is produced by the regression coefficient and Niño-3 index using the least squares technique, which is regarded as the ENSO-related component. Then, the ENSO-related component is subtracted from the original time series, and the residuals are regarded as the "ENSO free" parts.

\section{Snow cover effects over the central and eastern TP}

Routine meteorological observations over the TP, which has an average altitude greater than $4000 \mathrm{~m}$ above sea level, are lacking due to the severe environment and the sparse population. The density of surface meteorological stations within the TP is only 34 stations per $10^{6} \mathrm{~km}^{2}$. Most of the stations are located in the central and eastern TP, which makes for a significantly lower density than the average of 260 stations per $10^{6} \mathrm{~km}^{2}$ over China 


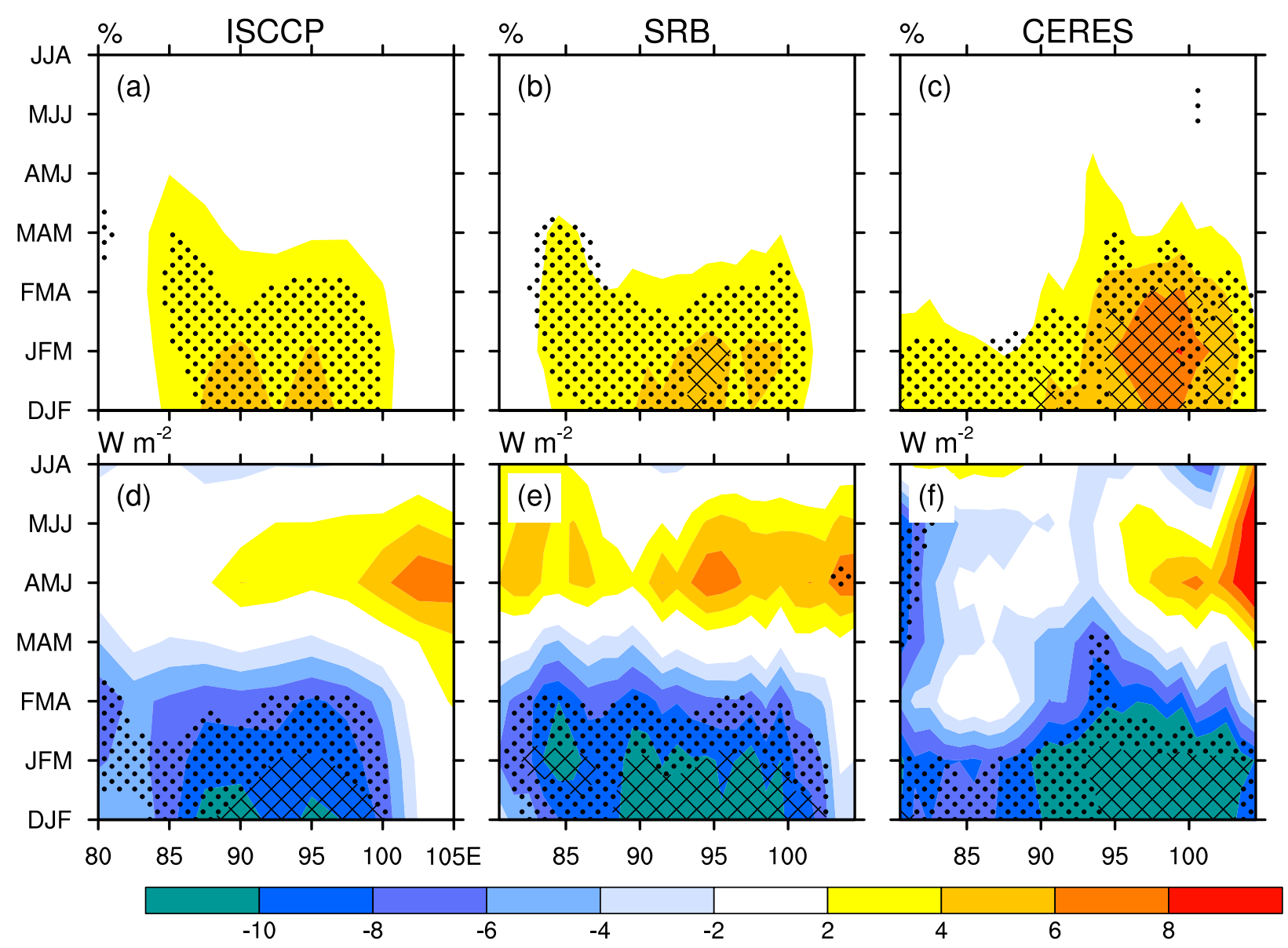

FIG. 3. Longitude vs three-month (in seven categories from DJF through JJA) differences in (a)-(c) surface albedo (\%) and (d)-(f) surface net shortwave radiation $\left(\mathrm{W} \mathrm{m}^{-2}\right.$ ) between above- and below-normal snow cover years based on the winter NSCD index averaged from $28^{\circ}$ to $38^{\circ} \mathrm{N}$ from radiation products: (left) ISCCP, (center) SRB, and (right) CERES.

(Duan et al. 2014). Thus, the snow cover across the plateau reported by previous studies exhibits large uncertainties (Chen et al. 2000; Zhang and Tao 2001; Xu et al. 2012; Wu et al. 2012b). Figure $1 b$ shows the interannual variation of the winter (December-February) NSCD index, averaged across 92 stations (Fig. 1a, black solid dots), for the period 1979-2011, over the central and eastern TP. The winters with a standardized NSCD index value greater than 0.6 are considered to be excessive snow cover years (i.e., 1982/83, 1988/89, 1989/90, 1992/93, 1994/95, 1995/96, 1997/98, 2004/05, and 2007/08), and those with a value less than -0.6 are considered to be deficient snow cover years (i.e., 1978/79, 1980/81, 1984/85, 1986/87, 1993/94, 1996/97, 1998/99, 2002/03, 2005/06, and 2009/10). The differences between excessive and deficient snow cover years, based on different snow datasets, are presented in Fig. 2. The results show that NSCDs are significantly different between excessive and deficient snow cover years (Fig. 2a), and the same is true for station-observed snow depth (Fig. 2b).
In terms of the satellite-derived snow datasets (Figs. 2c-f), the results are similar despite being less significant, and the satellite snow depth [Fig. 2c, improved by Dai and Che (2010)] generally performs better than other snow datasets compared with station observations. Snow cover anomalies are apparent in winter and spring (March-May) over most parts of the central and eastern TP in different snow datasets (Fig. 2); significant abnormal signals are only found in a few areas until June. In other words, winter snow cover cannot persist until summer, and most of the snow cover melts in late spring over the central and eastern TP.

\section{a. Snow-albedo effect}

The presence of snow cover may significantly change surface albedo, which is defined here as the ratio between surface upward and downward shortwave radiation. As shown in Figs. 3a-c, greater snow cover over the central and eastern TP increases surface albedo, and albedo anomalies quickly diminish after snow melts 

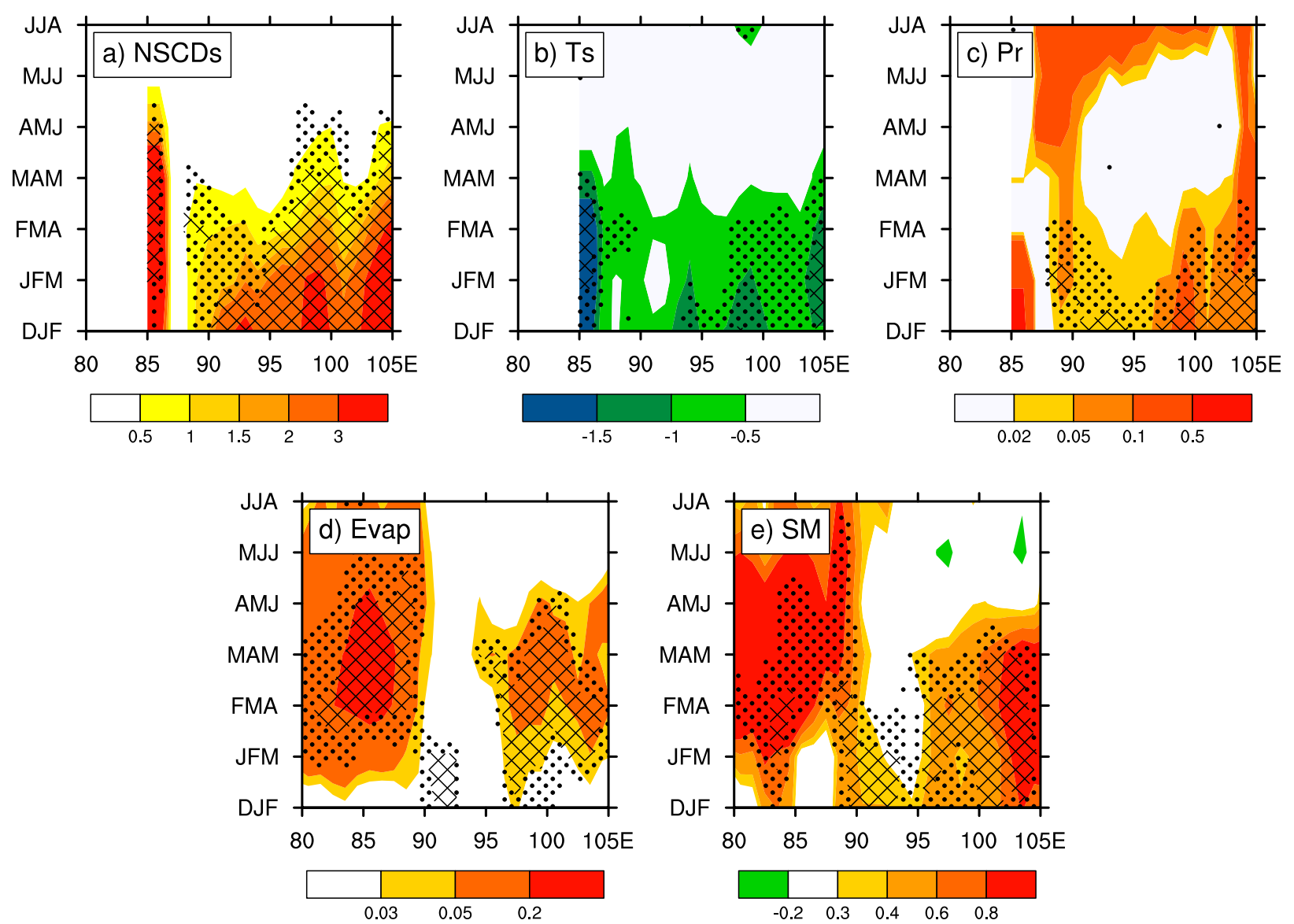

FIG. 4. Longitude vs three-month (in seven categories from DJF through JJA) differences in (a) the NSCDs (days), (b) surface temperature $\left({ }^{\circ} \mathrm{C}\right),(\mathrm{c})$ precipitation $\left(\mathrm{mm} \mathrm{day}^{-1}\right)$, (d) evapotranspiration $\left(\mathrm{mm} \mathrm{day}^{-1}\right)$, and (e) $0-10$-cm soil moisture $\left(\mathrm{kg} \mathrm{m}^{-2}\right)$, between aboveand below-normal snow cover years, based on the winter NSCD index; values are for station-observed data in (a)-(c) and GLDAS model output data in (d) and (e).

away in late spring (Fig. 2). The difference in surface net solar radiation, calculated by surface downward and upward shortwave radiation, between above- and below-normal snow cover years also vanishes in late spring (Figs. 3d-f), and the maximum difference occurs in winter (values up to $-18 \mathrm{~W} \mathrm{~m}^{-2}$ ). The results are highly similar in all three of the satellite datasets, and the evolution of albedo and radiation anomalies is consistent with snow anomalies (Fig. 2), although they disappear slightly earlier than the snow anomalies since the snow cover is very thin and aged after spring.

Compared with years of deficient snow cover, precipitation is weaker after April (Fig. 4c); thus, simultaneous snowfall contributes little to snow cover anomalies in late spring and early summer, and snow cover anomalies are largely the result of the persistence from the preceding winter and early spring. The snowalbedo effect accounts for the significant decrease in local temperature (Yasunari et al. 1991). As shown in Fig. 4b, local surface temperatures cool during years with greater snow cover. However, the cooling effect of snow cover on the surface may be very weak when snow cover is very thick (Gao et al. 2004). So, is the fact that the negative anomaly of surface temperature (Fig. 4b) disappears earlier than snow anomalies (Fig. 2) connected with snow thickness? This question is worth examining by investigating the cooling effect of snow cover on the atmospheric vertical temperature profile. The snow cover cooling effect is most significant in the lower troposphere during winter, and the cooling effect becomes smaller with time (Fig. 5). The tropospheric temperature is lower in April than in March, which may be attributable to the rapid snowmelt process in April, after which the cooling effect is almost undetectable in May (Fig. 5f). However, negative temperature anomalies occur in June, and then temperatures rise again in July. Finally, the temperature turns to a negative anomaly in August (Figs. 5g-i). Thus, the discontinuity in the tropospheric temperature anomaly from May to August cannot be explained by the snow cover anomaly 

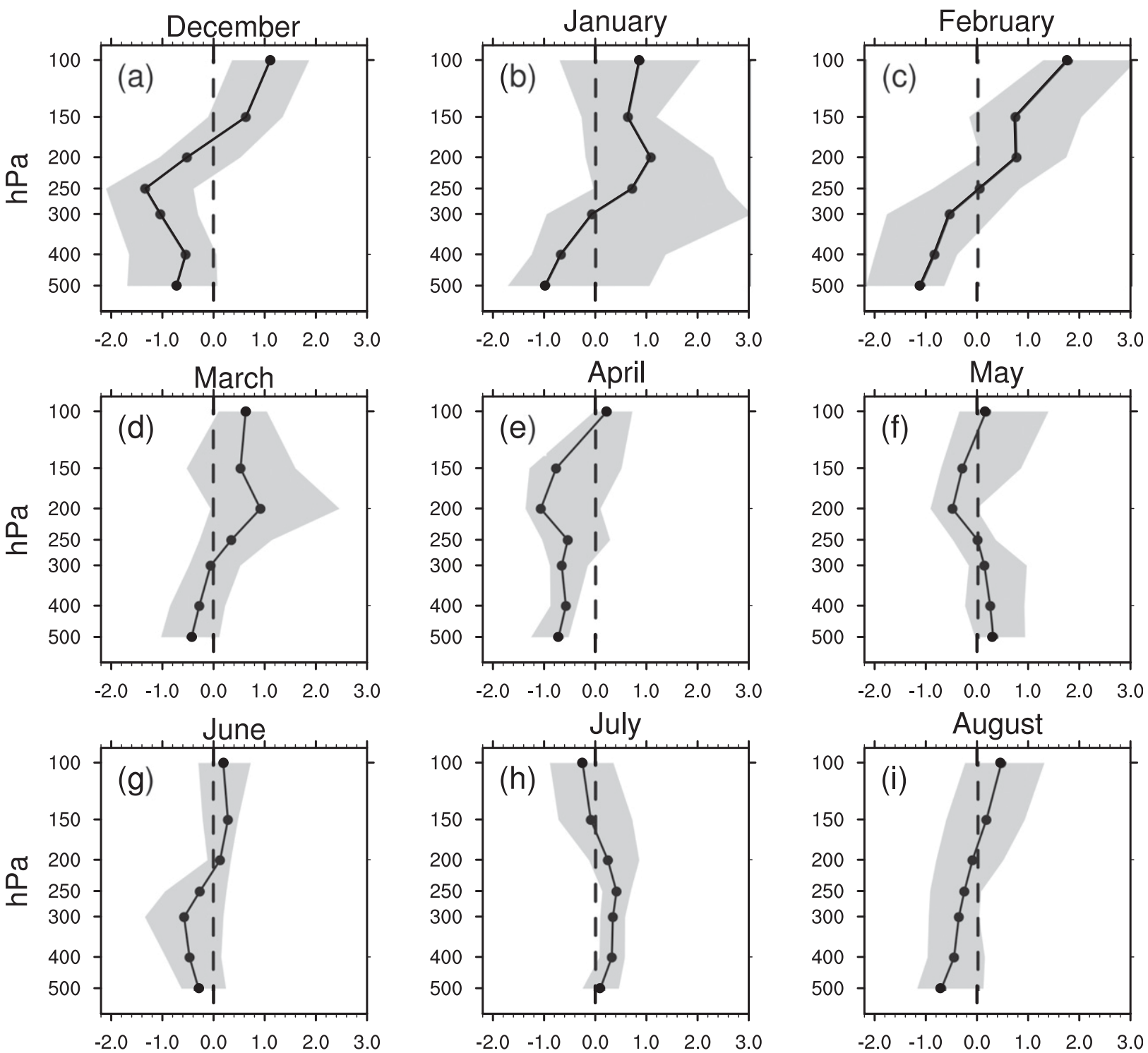

FIG. 5. Differences in the monthly [from (a) December through (i) August] vertical temperature profiles $\left({ }^{\circ} \mathrm{C}\right)$ between above- and below-normal snow cover years according to the winter NSCD index. Black solid lines indicate the average values of 16 radiosonde stations (Fig. 1a, purple open circles) and gray areas indicate the range in the values at the 16 radiosonde stations.

in the preceding winter and spring; rather, it is likely due to the adjustment of large-scale atmospheric circulation. Therefore, the preceding winter-spring snow cover anomaly in the central and eastern TP cannot influence the in situ summer tropospheric temperature.

\section{b. Snow-hydrology effect}

Figure $4 \mathrm{~d}$ indicates that summer evapotranspiration over the central and eastern TP is not enhanced during excessive winter snow cover years. The soil moisture anomaly is diminished in late spring over most parts of the central and eastern TP (Fig. 4e), indicating that it can only persist until June at approximately $100^{\circ} \mathrm{E}$. Over the central and eastern TP, both evapotranspiration and soil moisture anomalies induced by the preceding winter snow cover anomaly may not act as a bridge linking the winter snow anomaly and the subsequent EASM, although many previous studies (e.g., Barnett et al. 1989; Yasunari et al. 1991; Zhao et al. 2007; Zhu et al. 2009) suggested that soil moisture and evaporation might act as a bridge. The difference between our findings and previous results may be attributable to poor model performance, differences in experimental design, and the lack of credible observation data over the TP. For instance, the initial snow cover amounts in the models used are quite distinct; for example, the SWE over the 

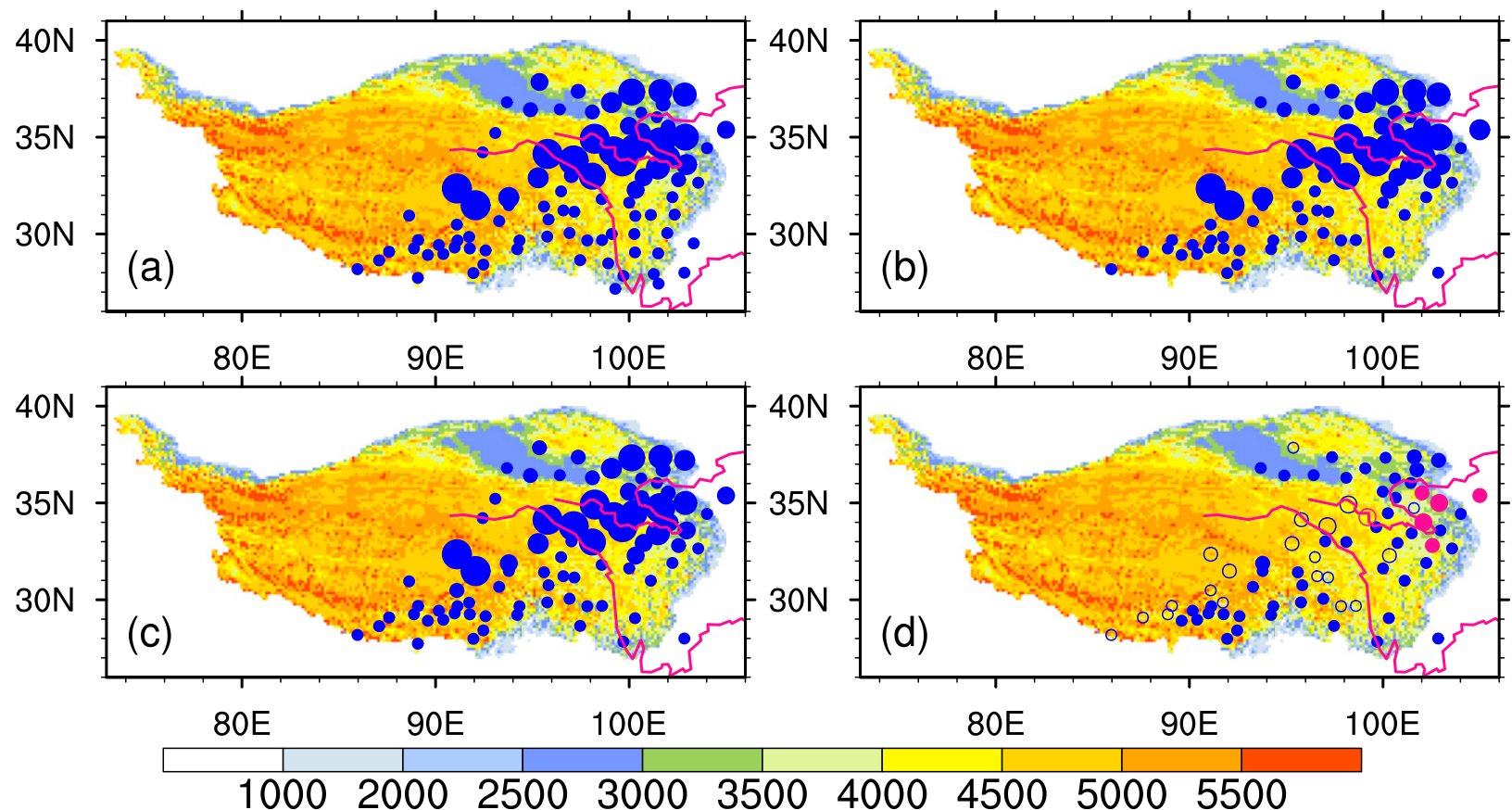
$0 \quad x<-5$
$\circ-2<=x<0$
- $2<=x<5$
$10<=x<15$
$20<=x<30$
$0-5<=x<-2 \quad 0<=x<2$
$5<=x<10$
$15<=x<20$
$x>=30$

FIG. 6. Spatial distributions of the depth of the upper boundary of frozen soil (different-size and filled-unfilled blue circles, $\mathrm{cm}$ ) in spring (March-May) based on station observations: (a) climatology; (b),(c) composites of above- and below-normal, respectively, snow cover years according to the winter NSCDs index; and (d) difference between (b) and (c) with red circles indicating results exceeding the $90 \%$ confidence level. Color shading shows topography $\geq 1000 \mathrm{~m}$ above sea level. The red curves represent the Yellow River and Yangtze River from north to south, respectively.

Eurasian continent was set to 2 and $5 \mathrm{~cm}$ by Barnett et al. (1989) and Yasunari et al. (1991), respectively, and the initial snow depth was set to as much as $20 \mathrm{~cm}$ by Zhu et al. (2009) over the entire TP. In fact, there is a large area of the TP without snow cover, even in winter (Qin et al. 2006; Pu et al. 2007).

Our recent study (Xiao and Duan 2015) found that snow cover usually melts completely after 20 days (without compensation from fresh snowfall), and the surface soil moisture anomaly can only persist for 20-25 days in April-June over the central and eastern TP. Snowfall events decrease from winter to summer; thus, the snow-albedo and snow-hydrology effects vanish within a month following the last snowfall event. The short persistence of the snow-hydrology effect may be attributable to frozen soil, because a significant portion of the TP is underlain by permafrost or seasonal frozen soil. The frozen soil decreases soil infiltration capacity, and the melting snow results in increased surface runoff and little absorption of the snow meltwater by the soil (Bayard et al. 2005). Most parts of the central and eastern TP are covered by frozen soil in spring, and a frozen soil layer to a depth of $20 \mathrm{~cm}$ underground occurs in limited areas of the central TP, particularly around the headwaters of the Yangtze and Yellow Rivers (Fig. 6a). The spatial distributions of frozen soil depth in above-normal (Fig. 6b) and below-normal (Fig. 6c) snow cover years are very similar to the climatological distribution, and the depth of the frozen soil differs little between above-normal and below-normal snow cover years (Fig. 6d). The thawing process in the area of the headwaters of the Yangtze and Yellow Rivers will release water into the soil, but saturated soil cannot absorb any snow meltwater or rainfall. Where the soil is not saturated, infiltration water will be absorbed, but to a limited extent. The rest of the central and eastern TP remains frozen in spring and inhibits the infiltration of snow meltwater. Robock et al. (2003) found similar results and argued that a later snowmelt period does not lead to wetter soil in spring across the mid- and high latitudes of the Eurasian continent.

Qin et al. (2006) indicated that snow cover is rare, or very thin or patchy, and lasts for only a short duration across the vast interior of the TP, and more than half of 
the snow mass is lost by sublimation in winter. There is only a small part of winter snow that turns to snow meltwater and is then absorbed by the soil. Thus, the winter snow cover over the central and eastern TP cannot have a significant impact on the EASM due to the limited persistence of snow-albedo and snowhydrology effects.

\section{Snow cover effects over the western TP and Himalayas}

Most of the areas with persistent snow cover are located in the southern and western edges of the TP within large mountain ridges and in the western part of the Yarlung Zangbo Valley (Pu et al. 2007). Based on a synthesis of satellite-derived SWE information and the percentage of visible snow in pixels with no microwavederived SWE, Liu et al. (2014a) defined the snow cover area proportion (SCAP) index for the TP region $\left(25^{\circ}-43^{\circ} \mathrm{N}, 64^{\circ}-105^{\circ} \mathrm{E}\right)$; that is, the grid points with SWE over $1 \mathrm{~mm}$ and snow cover percentage over $35 \%$ were assigned the number 1 , and other grid points were set to 0 . The index is highly correlated (coefficient of $0.5 ; 95 \%$ confidence level) in terms of interannual anomalies between May and summer (Liu et al. 2014b), and thus the SCAP index in May is employed here to identify potential mechanisms relating TP snow cover to the EASM.

The apparent heat source $Q_{1}$ (Yanai et al. 1973) is calculated as

$$
Q_{1}=C_{p}\left(\frac{p}{p_{0}}\right)^{k}\left(\frac{\partial \theta}{\partial t}+\mathbf{V} \cdot \nabla \theta+\omega \frac{\partial \theta}{\partial p}\right),
$$

where $\theta$ is the potential temperature, $\omega$ is the vertical $p$ velocity, $\mathbf{V}$ is the horizontal velocity, $p_{0}$ is the surface pressure, and $p$ is the pressure. In the equation $\kappa=R / C_{p}$, $R$ and $C_{p}$ are the gas constant and specific heat of dry air at constant pressure, respectively. Integrating the equation from the surface to $100 \mathrm{hPa}$, we obtain the air column apparent heat source. The interannual variations in winter NSCDs, summer $Q_{1}$, and the SCAP index, are shown in Fig. 7. In Fig. 7a, all of the variables are averaged for the central and eastern TP (Fig. 1a, red rectangle), and the summer ERA-Interim $Q_{1}$ exhibits a good relationship with the atmospheric heat source-sink (Duan and $\mathrm{Wu} 2008$ ) at the interannual time scale (correlation coefficient of 0.83 ; significant at the $99 \%$ confidence level). However, a weak relationship is found between winter NSCDs and summer $Q_{1}(0.19)$, indicating that winter snow cover over the central and eastern TP cannot significantly alter the summer heat source. In terms of the snow cover over the western TP and the Himalayas (Fig. 7b) in May, snow cover
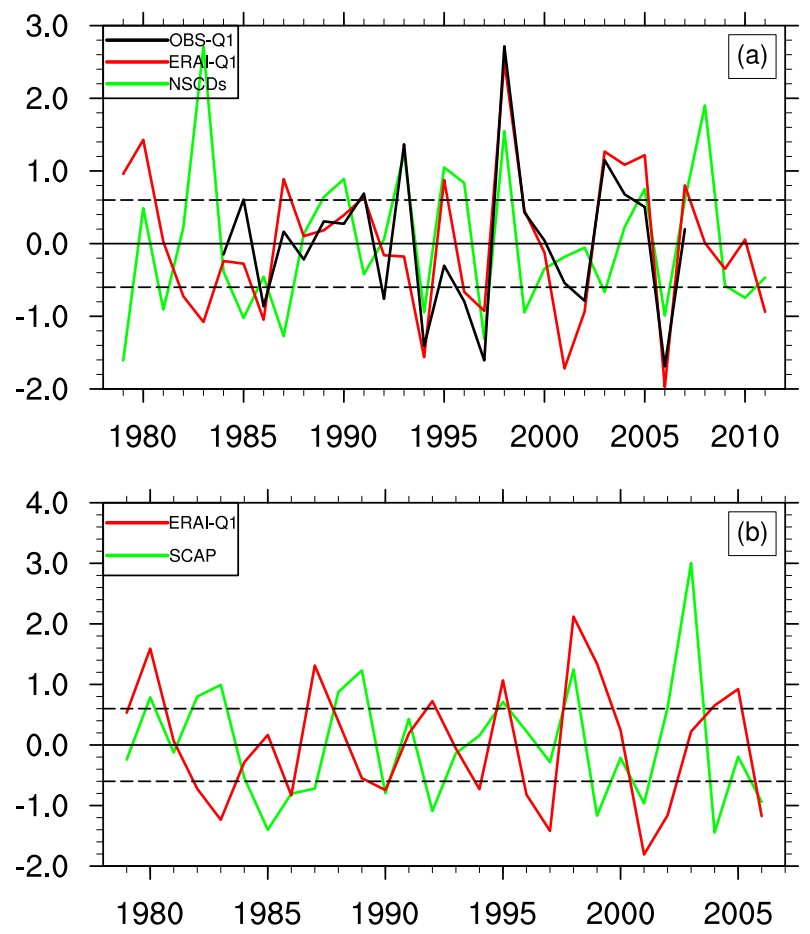

FIG. 7. The standardized interannual time series of the atmospheric apparent heat source and NSCD and SCAP indices across the TP: (a) NSCD index in winter (green line), summer ERA-Interim $Q_{1}$ (red line), and summer atmospheric heat source-sink (black line) over the central and eastern TP (ERA-Interim $Q_{1}$ interpolated to the 92 stations by bilinear interpolation); and (b) SCAP index over the western TP and Himalayas (green line) in May and the summer $Q_{1}$ (red line), averaged from the grid points with altitude $>3000 \mathrm{~m}$. Dashed lines indicate \pm 0.6 standard deviations.

displays a low lagged correlation with summer $Q_{1}$ (only $0.08)$, although it can persist into summer. Therefore, the preceding snow cover cannot significantly modulate the subsequent summer atmospheric heat source of the central and eastern TP, or the entire TP. The winterspring snow cover over the TP cannot influence the interannual variability of the EASM by altering the summer atmospheric heat source over the TP.

Standardized SCAP index (Fig. 7b, green line) values greater than 0.6 are defined as above-normal snow cover years, and those smaller than -0.6 as below-normal years. Each category contains nine samples; that is, the western TP and the Himalayas feature above-normal snow cover in nine years $(1980,1982,1983,1988,1989$, 1995, 1998, 2002, and 2003), and the other nine years (1985, 1986, 1987, 1990, 1992, 1999, 2001, 2004, and 2006) are below-normal snow cover years. Figure 8 a shows the climatological distribution of SWE over the TP in May, and we can see that snow mainly covers the western TP and stretches eastward along the Himalayas. According to the anomaly years mentioned above, snow cover is 


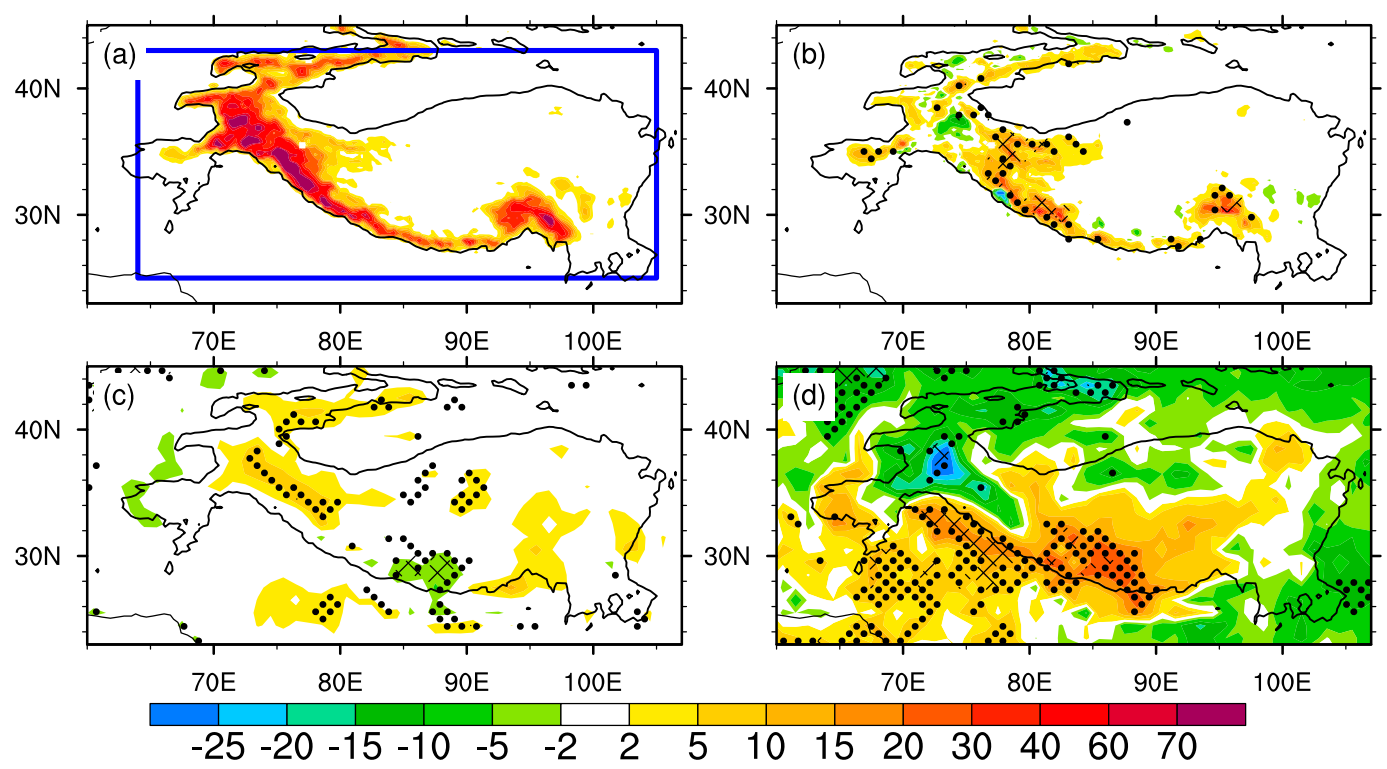

FIG. 8. Color shading showing the climatological spatial distribution of (a) SWE ( $\mathrm{mm}$ ) in May and the difference in (b) SWE (mm) obtained from NSIDC, (c) surface albedo (\%), and (d) surface net shortwave radiation (W m ${ }^{-2}$ ) derived from SRB between above- and below-normal TP snow cover years, according to the SCAP index for May (Fig. 7b, green line). The blue box in (a) indicates the domain used to define the SCAP index $\left(25^{\circ}-43^{\circ} \mathrm{N}, 64^{\circ}-105^{\circ} \mathrm{E}\right)$, and the black curve in all panels outlines the TP area with an averaged altitude $>2000 \mathrm{~m}$.

above normal across the TP (Fig. 8b), and there are two positive anomaly centers: the western TP at approximately $80^{\circ} \mathrm{E}$ and the southeastern TP at approximately $95^{\circ} \mathrm{E}$. The snow cover anomaly centers are still apparent in summer (Fig. 14d), demonstrating strong persistence in these places, as noted previously by Liu et al. (2014b). Although snow cover still exists over the western TP and the Himalayas in summer, surface albedo decreases because snow is getting old and thinning. Thus, the difference in surface albedo is small (Fig. 8c), and the snow-albedo effect plays only a weak role in weakening surface net solar radiation (Fig. 8d). In above-normal snow cover years, surface net solar radiation (Fig. 8d) is approximately $25 \mathrm{~W} \mathrm{~m}^{-2}$ less than that in below-normal years over the western TP, and the positive anomaly at approximately $86^{\circ} \mathrm{E}$ may be attributable to the negative albedo anomaly (Fig. 8c). Most parts of the TP show positive surface net solar radiation anomalies, even though snow cover is above normal. Because of the weak albedo anomaly in summer, the snow-albedo effect contributes little to reduce surface net radiation; thus, it is not unusual that snow cover over the TP is weakly related to the summer atmospheric heat source (Fig. 7b). This is not unexpected because the TP summer atmospheric heat source is influenced by surface conditions as well as other factors, such as the North Atlantic Oscillation (NAO; Liu and Duan 2012) and Indian Ocean basin mode (Hu and Duan 2015).
However, after removing the ENSO signal, a good relationship remains between TP SCAP and summer rainfall over the Yangtze and Yellow River basins (Fig. 9a, blue rectangle), as documented in previous studies (Zhang and Tao 2001; Y. S. Zhang et al. 2004; Souma and Wang 2010; Liu et al. 2014a,b), and the spatial pattern of the precipitation over East Asia shown in Fig. 9 is similar to the first leading mode of the summer precipitation in East Asia (Wang et al. 2008). As shown in Fig. 10, the correlation coefficients between SCAP and the summer precipitation over the Yangtze and Yellow River basins is 0.56 , with a confidence level of $99 \%$, according to the Student's $t$ test. Excessive spring snow cover over the western TP and the Himalayas typically corresponds to abundant summer precipitation over the Yangtze and Yellow River basins, except during two years (1988 and 2002), and deficient snow cover is usually followed by a dry summer, with only one year (1987) featuring slightly above-normal precipitation. The existence of mismatched samples supports the idea that the interannual variability of EASM rainfall is highly complicated (Wang et al. 2008) and cannot be fully explained by one factor, despite the robust relationship between SCAP index and the summer precipitation over the Yangtze and Yellow River basins found here. Other factors such as ENSO (Wang et al. 2000), ENSO and NAO combined ( $\mathrm{Z}$. Wu et al. 2009; Wu et al. 2012a), the Indian Ocean basin mode (Yang et al. 


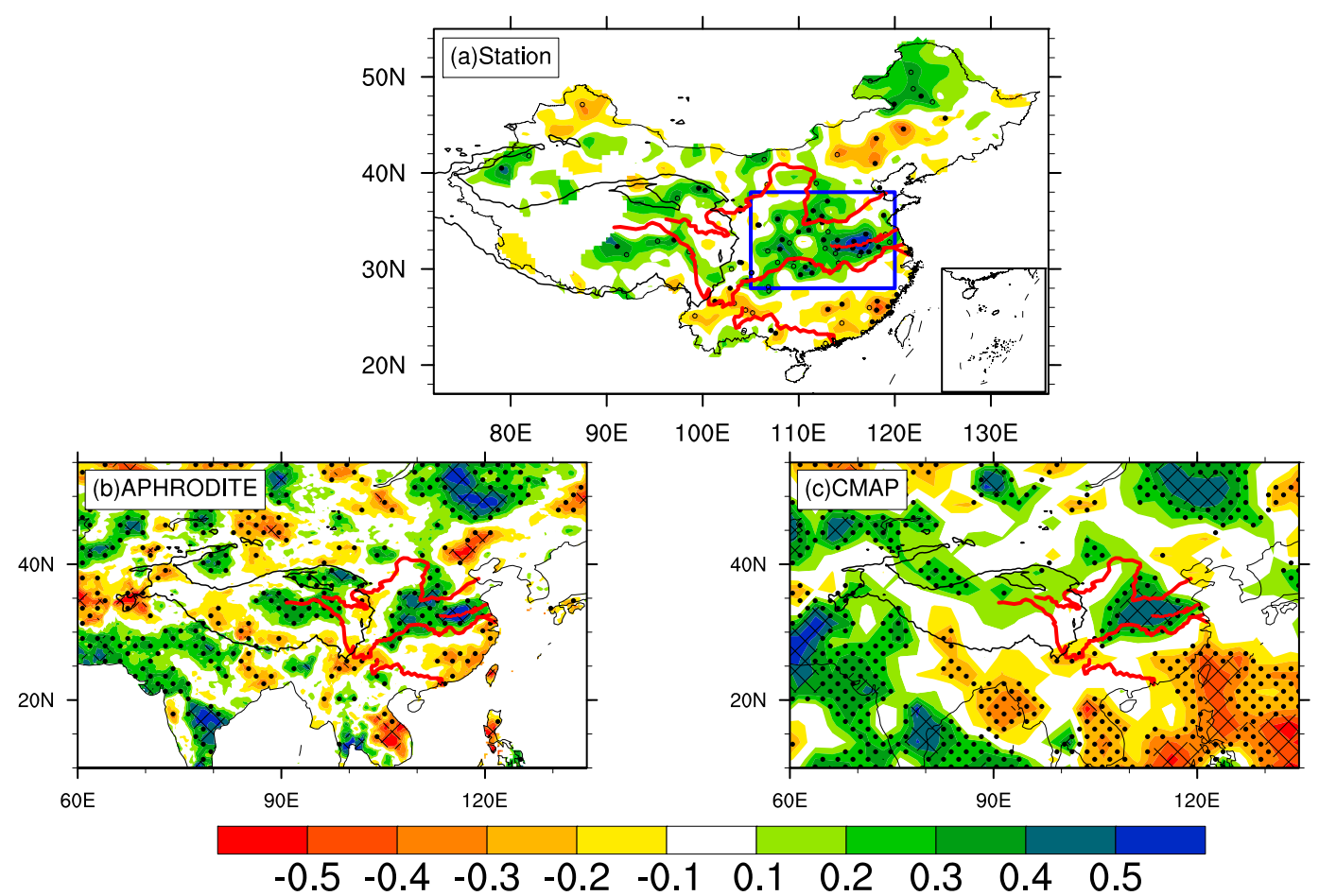

FIG. 9. Color shading showing the correlation coefficients between the May SCAP index and summer precipitation for the period 1979-2006 for (a) station-observed data, (b) APHRODITE, and (c) CMAP. The ENSO signals have been removed from all of the variables. The blue rectangle in (a) denotes the Yangtze and Yellow River basins $\left(28^{\circ}-38^{\circ} \mathrm{N}, 105^{\circ}-120^{\circ} \mathrm{E}\right)$. In (a), the small open (solid) circles indicate statistical significance at the $90 \%$ $(95 \%)$ confidence level; and in (b) and (c), the dots and cross-hatching are as in Fig. 2. The red curves represent, from north to south, the Yellow, Huaihe, Yangtze, and Zhujiang Rivers. The black curve outlines the TP area with an average altitude $>3000 \mathrm{~m}$.

2007), the Arctic Oscillation (Gong et al. 2011), and Arctic sea ice (B. Wu et al. 2009) may also play important roles. It is worth noting that 1987 and 1988 were ENSO years, and the spring surface sensible heat flux over the mid-to-high latitudes of the Eurasian continent may have had an influence on the summer precipitation over eastern China in 1987 and 2002 (Wu et al. 2015).

The link between snow cover and the EASM is likely based on two physical processes. One is the snowalbedo effect, but the albedo effect is weak in summer, as discussed above. Thus, there is only one way that the preceding snow cover could noticeably influence the EASM: the snow-hydrology effect. After removal of the ENSO signal, the regression of summer evapotranspiration against the SCAP index (Fig. 11a) demonstrates that surface evapotranspiration is reduced in the drainage area of the Yangtze and Yellow Rivers; thus, abovenormal precipitation between the Yangtze and Yellow Rivers does not result from local evapotranspiration. However, evapotranspiration is enhanced over the TP, and the enhanced evapotranspiration area corresponds to the snow cover anomaly centers (Fig. 8b), which themselves result from snowmelt runoff or snow meltwater infiltrating into soil in summer, benefitting the enhancement of evaporation (Barnett et al. 1989; Yasunari et al. 1991; Y. S. Zhang et al. 2004). While the enhanced evapotranspiration delivers more water vapor to the atmosphere, local rainfall does not increase (Fig. 9); thus, abundant water vapor originating from the western and southern TP can be conveyed eastward (Fig. 11b) by the westerly winds in the mid- and lower troposphere over the TP. In addition, there are two other vapor sources. One derives from the Bay of Bengal and is conveyed to eastern China by southwest winds, and the other arrives there by the enhanced summer northwest Pacific subtropical high. Liu et al. (2014a) explained that the subtropical high enhances due to excessive snow cover over the western TP. The excessive snow cover over the western TP is conducive to in situ downward motion and is connected with the upward motion over the north Indian Ocean through meridional circulation, which results in more precipitation (Fig. 9) and forces a Kelvin wave response with easterly wind anomalies (Fig. 11b) over the tropical 


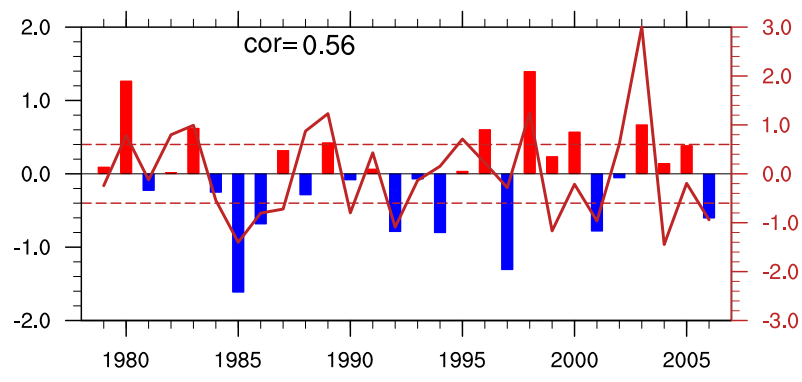

FIG. 10. Time series of the summer precipitation anomaly (bars, $\left.\mathrm{mm} \mathrm{day}^{-1}\right)$ over the Yangtze and Yellow River basins $\left(28^{\circ}-38^{\circ} \mathrm{N}\right.$, $105^{\circ}-120^{\circ} \mathrm{E}$ ), based on station-observed precipitation and standardized May SCAP index (brown line). Dashed lines represent \pm 0.6 standard deviations of the SCAP index.

oceans. Ultimately, summer precipitation is reduced over the northwestern Pacific and the northwest Pacific subtropical high is enhanced (Xie et al. 2009).

In terms of mean climate, the net total water vapor flux, integrated from the surface to $300 \mathrm{hPa}$, transported to the Yangtze and Yellow River basins (Fig. 12a, blue rectangles), is approximately $466 \mathrm{~kg} \mathrm{~m}^{-1} \mathrm{~s}^{-1}$ in summer. The prevailing southerly wind provides a large amount of the water vapor, alongside another vapor source coming from the western boundary $\left(105^{\circ} \mathrm{E}\right.$, including the $\mathrm{TP}$ and the Bay of Bengal water vapor supply), downstream of the TP. A portion of the vapor is transported eastward and northward, but during excessive snow cover years (Fig. 12b) the northward vapor transport through the northern boundary $\left(38^{\circ} \mathrm{N}\right)$ decreases remarkably. Water vapor transport through the remaining boundaries is enhanced, which is conducive to abovenormal precipitation over eastern China, as shown in Fig. 9. The opposite situation occurs during years of deficient snow cover (Fig. 12c), with precipitation suppressed over the Yangtze and Yellow River basins. Figure $12 \mathrm{~d}$ shows that, in above-normal snow cover years, net incoming water vapor is $184 \mathrm{~kg} \mathrm{~m}^{-1} \mathrm{~s}^{-1}$ larger than that during deficient snow cover years. The net water vapor can be mainly ascribed to the southerly anomalies (Fig. 11b), and partly to the vapor transportation eastward from the TP and the Bay of Bengal. While there is a positive anomaly of water vapor transport to the Yangtze and Yellow River basins through the northern boundary, this does not mean that more water vapor is coming from northern China, because water vapor continues to be transported northward through the northern boundary, as shown in Fig. 12b. Northward water vapor transport simply decreases compared with years of deficient snow cover.

The eastward propagation of the low-level vortices that originate over the TP plays a highly significant role in stimulating heavy rainfall over eastern China (Tao
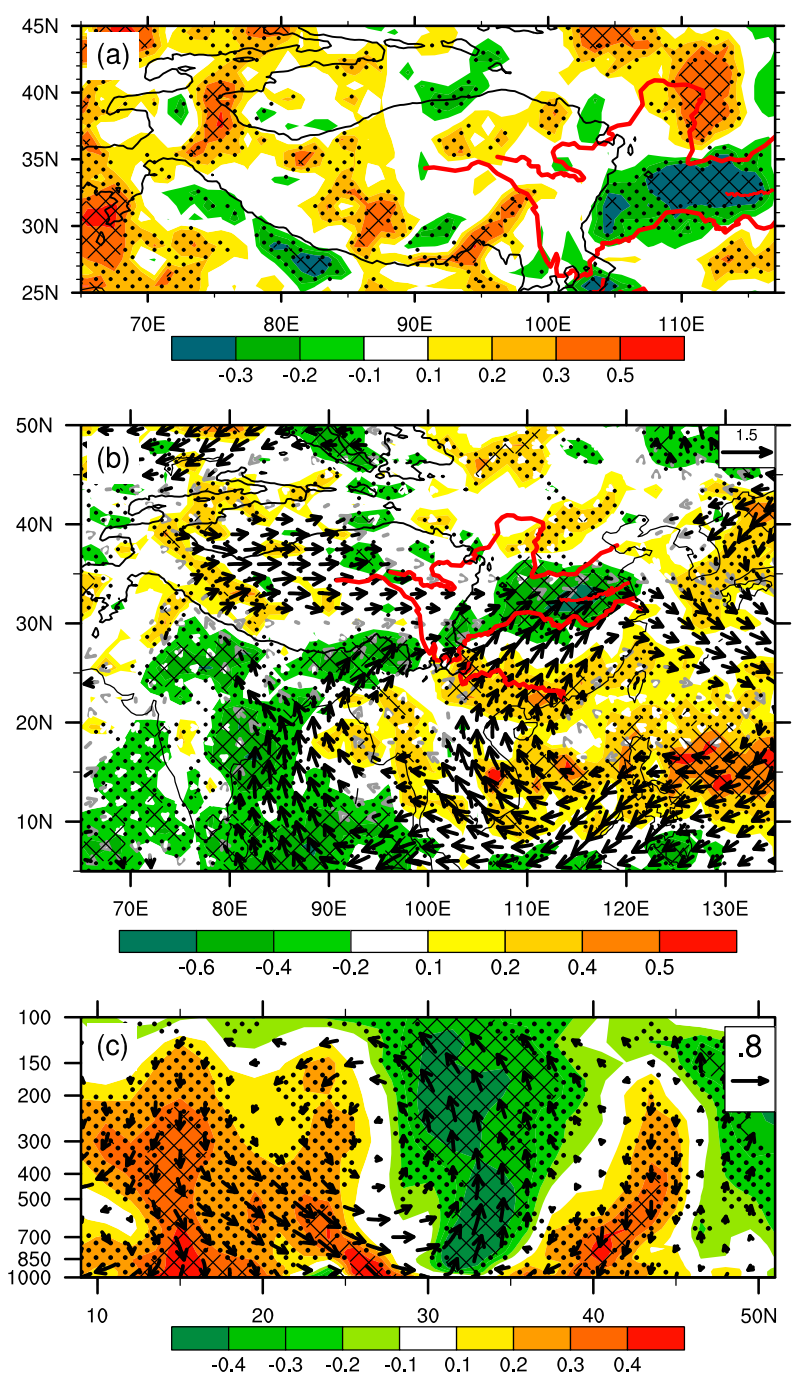

FIG. 11. (a) Regression coefficients of summer evapotranspiration (obtained from GLDAS, color shading, $\mathrm{mm} \mathrm{day}^{-1}$ ) regressed against the May SCAP index, (b) vertically integrated (surface to $300 \mathrm{hPa}$ ) water vapor flux (vectors, $\mathrm{kg} \mathrm{m}^{-1} \mathrm{~s}^{-1}$ ) and water vapor flux divergence (color shading, $10^{-5} \mathrm{~kg} \mathrm{~m}^{-2} \mathrm{~s}^{-1}$ ), and (c) the pressure-latitude cross section for vectors composed of meridional velocity $\left(\mathrm{m} \mathrm{s}^{-1}\right)$ and vertical velocity (color shading, $10^{-2} \mathrm{~Pa} \mathrm{~s}^{-1}$ ) averaged from $110^{\circ}$ to $120^{\circ} \mathrm{E}$ for the period $1979-2006$. The ENSO signals have been removed from all of the variables. Black vectors exceed the $95 \%$ confidence level based on a Student's $t$ test. The red curves represent, from north to south, the Yellow, Huaihe, Yangtze, and Zhujiang Rivers.

and Ding 1981; Yasunari and Miwa 2006). The average time-longitude cross section of vorticity at $500 \mathrm{hPa}$ from $28^{\circ}$ to $38^{\circ} \mathrm{N}$ (Fig. 13a) shows that frequent positive vorticity anomalies propagate eastward to the Yangtze and Yellow River basins, and most of the positive vorticity anomalies are generated over the western TP, which corresponds to the western TP snow cover anomaly center (Fig. 8b). Although most of the water vapor is 

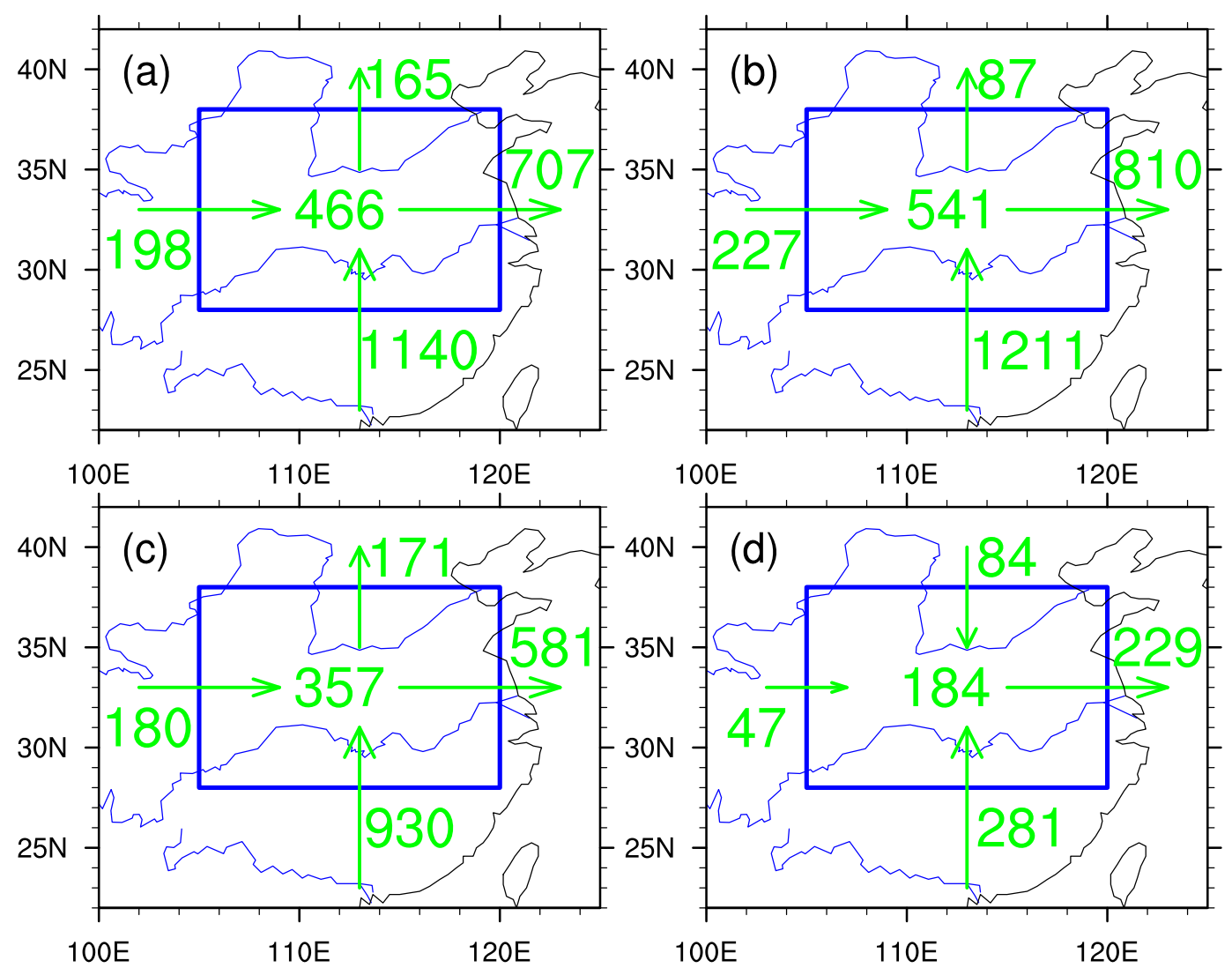

FIG. 12. Vertically integrated summer water vapor flux values $\left(\mathrm{kg} \mathrm{m}^{-1} \mathrm{~s}^{-1}\right)$ from the surface to $300 \mathrm{hPa}$ through each boundary of the Yangtze and Yellow River basins (blue rectangle; $28^{\circ}-38^{\circ} \mathrm{N}, 105^{\circ}-120^{\circ} \mathrm{E}$ ), based on ERAInterim data (green arrows indicate the direction of water vapor flux): (a) climatology; (b) composite of the abovenormal snow cover years based on the May SCAP index; (c) as in (b), but for the below-normal snow cover years; and (d) the difference between (b) and (c). The blue curves represent, from north to south, the Yellow, Yangtze, and Zhujiang Rivers.

transported to the Yangtze and Yellow River basins along the southern boundary, the positive vorticity anomalies do not propagate through the southern boundary (i.e., the southerly anomaly does not favor the propagation of synoptic disturbances northward; Fig. 13b). While the snow cover of the western TP and the Himalayas only contributes a small part of the water vapor to the summer precipitation anomaly over the Yangtze and Yellow River basins, the eastward-propagating synoptic disturbances generated over the TP may be an important trigger for summer precipitation over eastern China. As shown in Fig. 11a, surface evapotranspiration is markedly enhanced over the TP, and the frequent synoptic disturbances seem to be attributable to an evaporation-convection feedback mechanism (Yasunari et al. 1991; Y. S. Zhang et al. 2004). The eastward-propagating synoptic disturbances and lowlevel convergence intensify the upward motion over the Yangtze and Yellow River basins (Fig. 11c). The probability distribution functions of daily precipitation over the
Yangtze and Yellow River basins reveal that there are more light rain $\left(<10 \mathrm{~mm} \mathrm{day}^{-1}\right)$ and moderate rain (10-18 $\mathrm{mm} \mathrm{day}^{-1}$ ) events during excessive snow cover years than in deficient snow cover years. Heavy rain (25-50 $\mathrm{mm} \mathrm{day}^{-1}$ ) also enhances, which does not occur during deficient snow cover years (Fig. 13c). Our findings are similar to those of Wang et al. (2014a).

Snow cover over the western TP and the Himalayas affects the EASM by modulating large-scale atmosphere circulation, which is beneficial to the water vapor supply, and the regionally enhanced evapotranspiration favors an increased number of synoptic disturbances. Ultimately, convergence forms over the Yangtze and Yellow River basins, induced by water vapor convergence and the eastward-propagating synoptic disturbances from the TP.

\section{Model simulation}

To confirm the conclusions obtained from data analyses, the Weather Research and Forecasting (WRF) 
(a)

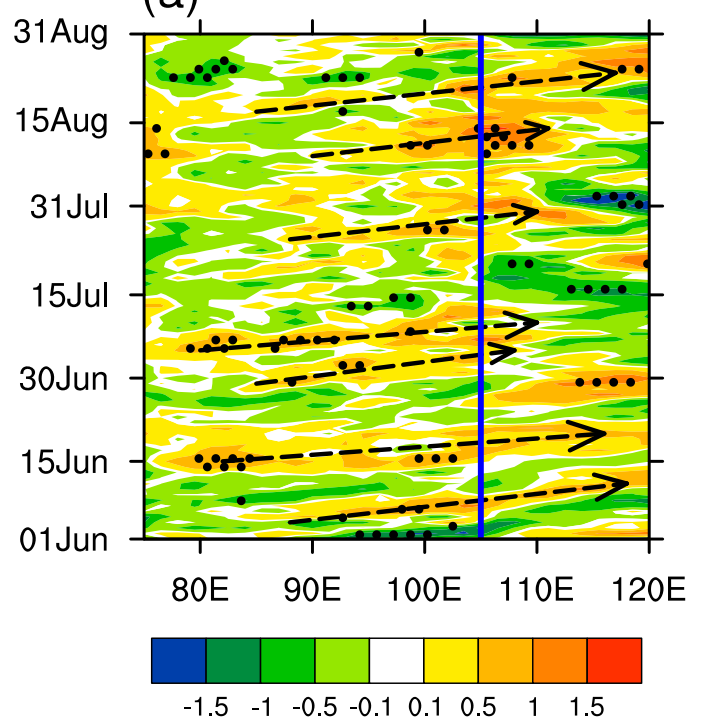

(b)

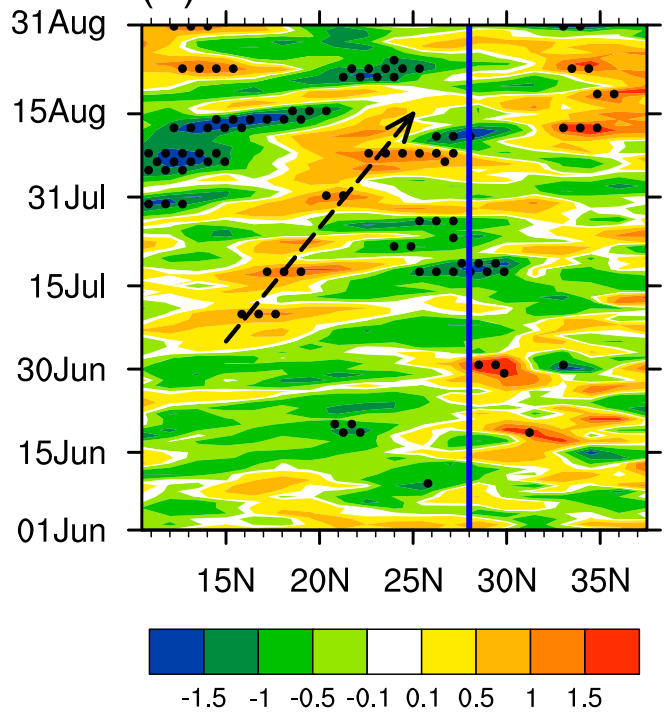

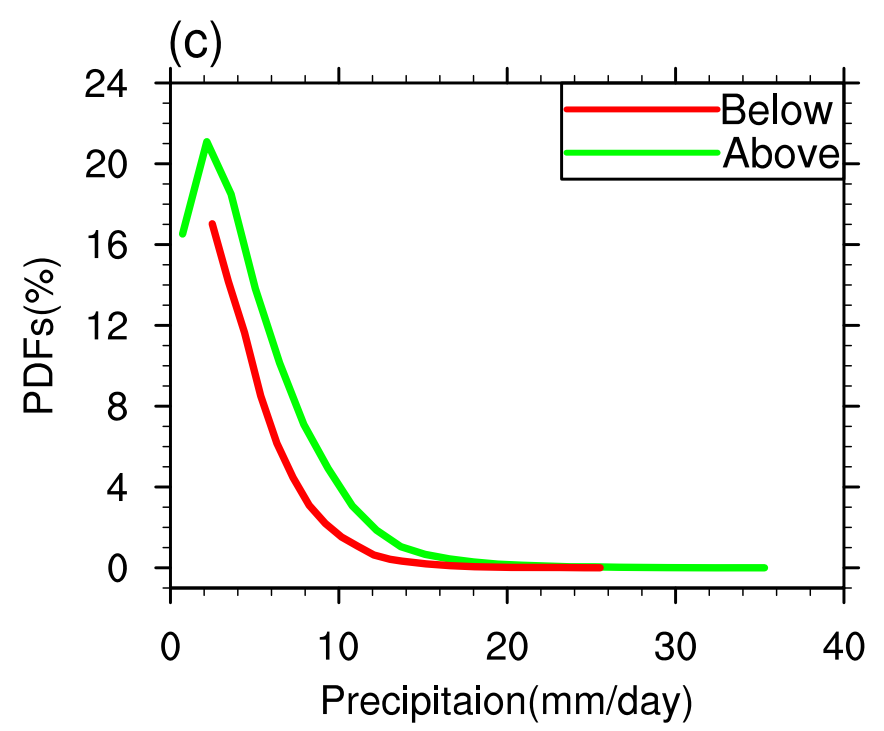

FIG. 13. Differences in summer 500-hPa vorticity (color shading, $10^{-5} \mathrm{~s}^{-1}$ ) between above- and below-normal SCAP years for the vorticity averaged in (a) from $28^{\circ}$ to $38^{\circ} \mathrm{N}$ with the blue line indicating $105^{\circ} \mathrm{E}$, and (b) from $105^{\circ}$ to $120^{\circ} \mathrm{E}$ with the blue line indicating $28^{\circ} \mathrm{N}$. The arrows indicate the transportation direction of positive vorticity. (c) The probability distribution functions of daily summer precipitation over the Yangtze and Yellow River basins $\left(28^{\circ}-38^{\circ} \mathrm{N}, 105^{\circ}-120^{\circ} \mathrm{E}\right)$ for above- (green) and below-normal (red) snow cover years.

Model version 3.6 (http://www2.mmm.ucar.edu/wrf/ users/docs/user_guide_V3/ARWUsersGuideV3.pdf) is employed here. WRF has a good performance on the simulation of EASM (Wang et al. 2014b). It is forced by snow cover anomalies over the TP area in May.

The physical packages employed in WRF version 3.6 include the WSM-6 microphysics scheme, the RRTM longwave scheme, the Dudhia shortwave scheme, the Noah land surface model, the BouLac planetary boundary layer scheme, and the Grell-Devenyi convective scheme. The simulation domain is shown in
Fig. S1 in the supplementary material. The WRF Model is driven by climatological (1981-2010) initial and lateral boundary conditions, including 6-hourly ERA-Interim and daily Optimum Interpolated Sea Surface Temperature (OISST) data (Reynolds et al. 2007). The model has a $45-\mathrm{km}$ horizontal resolution (without nested grids in this study) and 38 terrainfollowing vertical sigma levels spanning from the surface to $50 \mathrm{hPa}$. Three ensemble experiments are performed; namely, a control experiment, an abovenormal snow experiment (ANexp), and a below-normal 

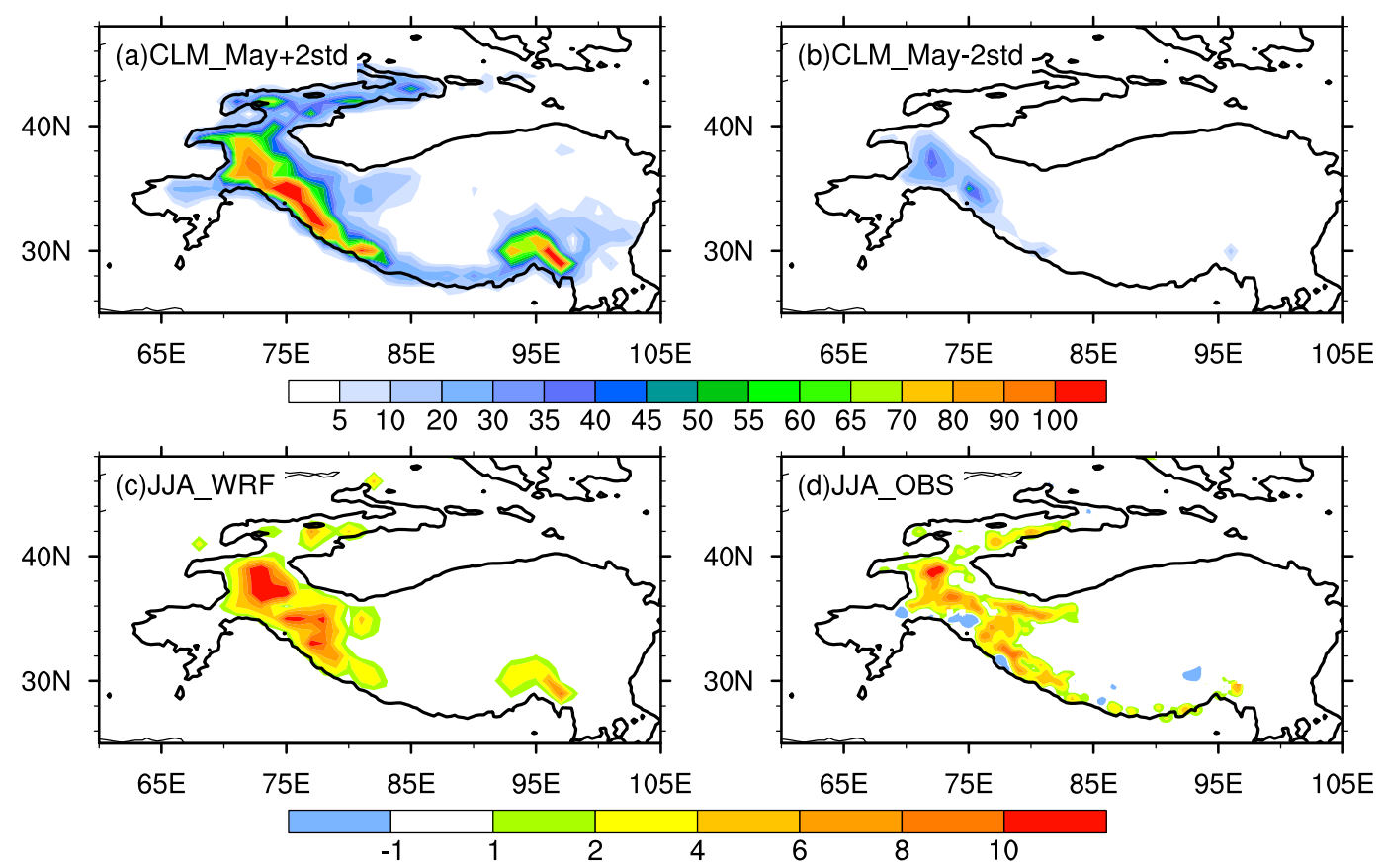

FIG. 14. Color shading showing the distributions of SWE (mm) over the TP: (a) ANexp in May; (b) BNexp in May; (c) difference in summer SWE between ANexp and BNexp; and (d) and the difference in summer NSIDC SWE between above- and below-normal TP snow cover years, according to the May SCAP index. The black curve outlines the TP area with an average altitude $>2000 \mathrm{~m}$.

snow experiment (BNexp). Each of the ensemble experiments contains six members with different initial conditions starting from 0000 UTC 1 May, and each simulation ends at 1800 UTC 31 August. We find that the WRF Model reproduces the South Asian high at $200 \mathrm{hPa}$ and western Pacific subtropical high at $500 \mathrm{hPa}$ well, apart from stronger southerlies at $850 \mathrm{hPa}$ and heavier precipitation over eastern China (Fig. S2 in the supplementary material). Based on NSIDC satelliteobserved SWE, the climatological SWE in May plus twice the standard deviation obtains the forcing field for ANexp, whereas the forcing field for BNexp is obtained by means of minus twice the standard deviation from the climatological SWE, as shown in Figs. 14a and 14b. The distributions of SWE in these figures are deemed reasonable because they are very similar to the SWE found to have occurred in May 1981 and 2004 (figure omitted). The SWE is reset with the same distribution every two days in May and then freely adjusted from 1 June.

Consistent with the data diagnosis results reported in section 4, the simulated SWE over the TP is able to maintain its anomaly from spring to summer (Fig. 14c) and presents a spatial pattern very similar to observations (Fig. 14d); that is, the most persistent snow is located over the western and southeastern TP, as documented by Pu et al. (2007). The results demonstrate the capability of the WRF Model in simulating the seasonal variation of snow cover and depth over the TP, and this provides us with the necessary confidence to conduct the following analysis.

Figure 15a shows the summer differences in vertical motion within $110^{\circ}$ and $120^{\circ} \mathrm{E}$ between the ANexp and BNexp results. Clearly, the vertical motion is enhanced along $34^{\circ} \mathrm{N}$ in ANexp, similar to the data diagnosis results (Fig. 11c). The difference fields (between ANexp and BNexp) of summer precipitation and atmospheric column water vapor flux are plotted in Fig. 15b, and we can see that the above-normal snow in May is conducive to water vapor divergence over the TP in summer due to the weaker heating rate, corresponding to suppressed local precipitation. Meanwhile a noticeable positive rainfall belt, together with a moisture convergence zone, extends from the middle reaches of the Yangtze River to northern China (Fig. 15b), which again resembles the observed results (Fig. 9). Owing to the model bias and/or experiment design, the main rainfall belt is simulated at a slightly northward location, the eastward transportation of water vapor originated from the TP is weaker than observed, and the observed anticyclone anomaly over the South China Sea moves to Indochina.

But how does the positive rainfall belt anomaly downstream of the TP respond to the snow cover 

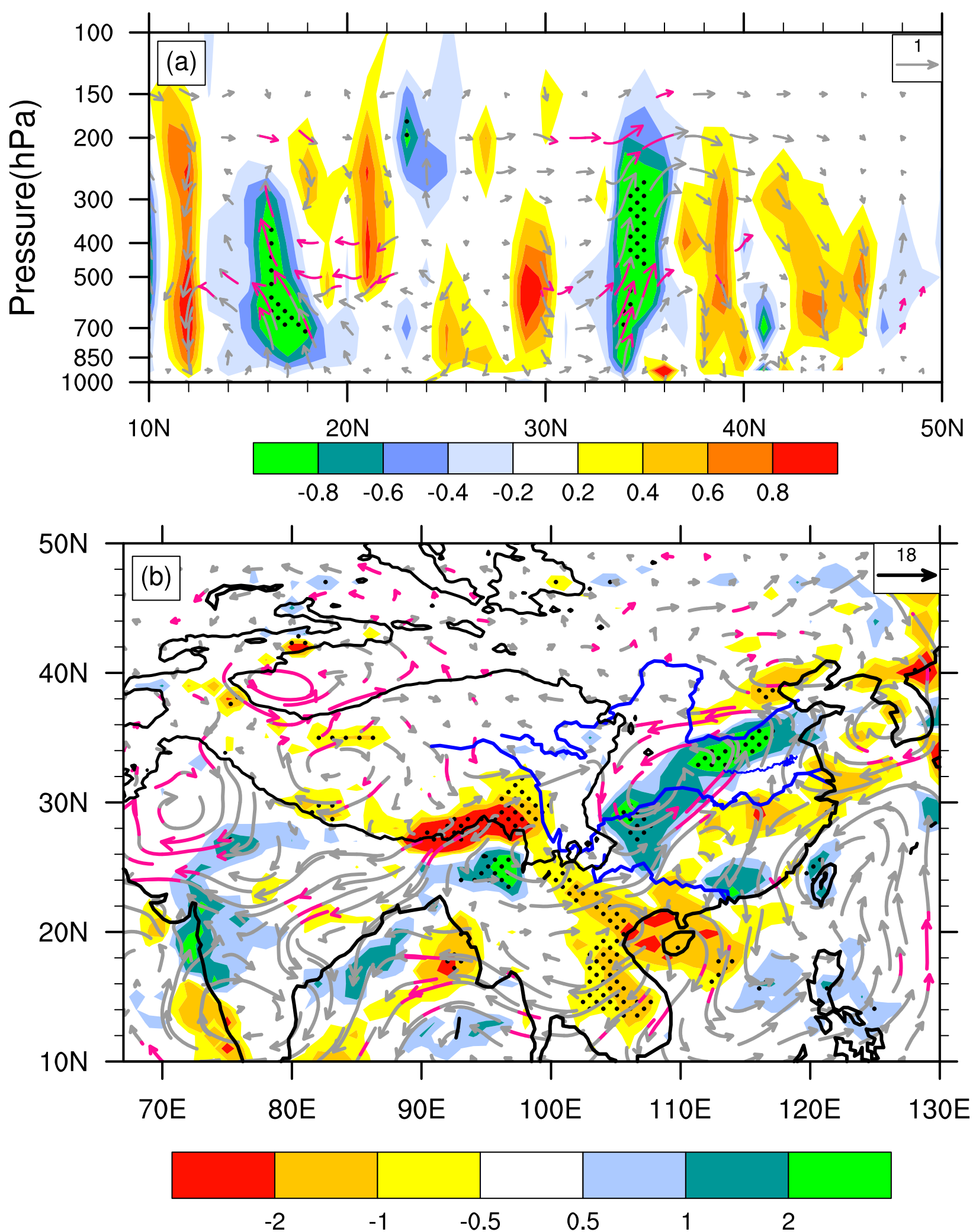

FIG. 15. Difference fields between ANexp and BNexp in summer: (a) pressure-latitude cross section of the vectors composed of meridional velocity $\left(\mathrm{m} \mathrm{s}^{-1}\right.$ ) and vertical velocity (color shading, $10^{-2} \mathrm{~Pa} \mathrm{~s}^{-1}$ ), averaged from $110^{\circ}$ to $120^{\circ} \mathrm{E}$; (b) precipitation (color shading, $\mathrm{mm} \mathrm{day}^{-1}$ ) and atmospheric column water vapor flux (vectors, $\mathrm{kg} \mathrm{m}^{-1} \mathrm{~s}^{-1}$ ) integrated from the surface to $300 \mathrm{hPa}$. The dotted areas and red vectors in (b) indicate statistical significance at the $95 \%$ confidence level. The black curve in (b) outlines the TP area with an average altitude $>2000 \mathrm{~m}$. 

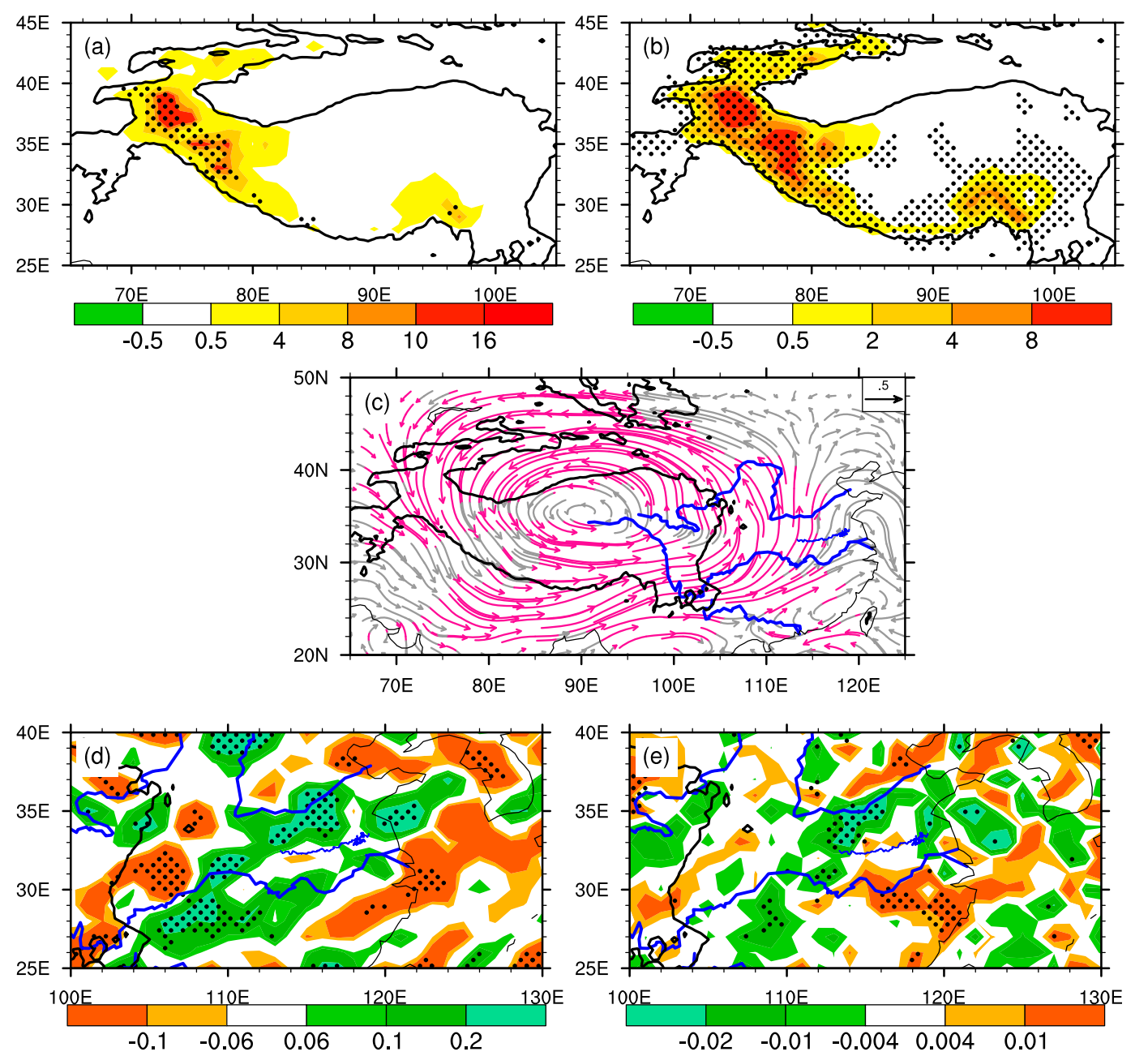

FIG. 16. Difference fields between ANexp and BNexp in summer: (a) SWE (mm); (b) surface albedo (\%); (c) 200-hPa wind field $\left(\mathrm{m} \mathrm{s}^{-1}\right)$; (d) 200-hPa divergence $\left(\mathrm{s}^{-1}\right)$; (e) 500-hPa vertical velocity $\left(\mathrm{Pa} \mathrm{s}^{-1}\right)$. The dotted areas and red vectors indicate statistical significance at the $95 \%$ confidence level. The black curve outlines the TP area with an average altitude $>2000 \mathrm{~m}$. The blue curves in (c)-(e) represent from north to south, the Yellow, Huaihe, and Yangtze Rivers.

anomaly over the TP? As discussed above, the snow anomaly over the western TP and Himalayas can last until summer (Fig. 16a), leading to reduced local net shortwave radiation via the snow-albedo effect (Fig. 16b). Thus, the TP surface cools down and weakens the South Asian high in summer (Fig. 16c), which further enhances the upper pumping effect (Fig. 16d) and benefits ascending motion (Fig. 16e) between the Yangtze and Yellow River basins. According to Liu et al. (2001), the vorticity equation can be simplified as

$$
\frac{\partial \zeta_{z}}{\partial t} \propto \frac{f+\zeta}{\theta_{z}} \frac{\partial Q}{\partial z}, \quad \theta_{z} \neq 0
$$

over the subtropical region in summer. Thus, the latent heat released by condensation of precipitation increases with height in the lower troposphere, resulting in the generation of positive vorticity and a cyclonic circulation anomaly in the lower troposphere. In the mid- and upper troposphere, however, the heating rate decreases with height above the heating center, induces a negative vorticity anomaly, and intensifies upper tropospheric divergence. Therefore, the positive feedback of circulation and diabatic heating enhances local vertical motion and then benefits above-normal summer precipitation between the Yangtze and Yellow River basins.

With the WRF Model driven by satellite SWE (SWE forcing from 1 January to 30 April) over the central and eastern TP in another experiment, the anomalies in the summer wind field and precipitation between the Yangtze and Yellow River basins are not apparent (figure not shown). Nevertheless, the numerical simulations confirm that the snow cover anomalies over the western TP and the Himalayas can influence the 
EASM, mainly by modulating the circulation and moisture conditions.

\section{Discussion and conclusions}

Based on observational data from multiple sources for the period 1979-2011, this paper primarily discusses the relationship between TP snow cover and the EASM in terms of the snow-albedo and snow-hydrology effects. The results show that winter snow cover over the central and eastern TP may not influence the EASM due to its short-term albedo and hydrology effects, and winter snow cover can only persist into late spring. Winter snow cover simultaneously exerts a considerable cooling effect on local air temperature through decreasing surface net solar radiation, and the pervasiveness of frozen soil across the TP explains the short-term snow-hydrology effect to some degree.

Although snow cover persists over the western TP and the Himalayas from May to summer, the snow-albedo effect is unimportant, and thus the cooling effect on air temperature is relatively weak. Further analysis indicates that there is a poor relationship between snow cover and the summer atmospheric heat source in either the central and eastern TP or the entire TP. Snow cover over the TP may not influence the EASM by altering local summer atmospheric heat sources, but the snow cover over the western TP and the Himalayas may influence the EASM by providing more water vapor from local evapotranspiration, generating eastwardpropagating synoptic disturbances over the TP and modulating water vapor transport routes via the southerly anomaly over southern China. Excessive precipitation then occurs between the Yangtze and Yellow River basins, which is stimulated by water vapor convergence and eastward-propagating synoptic disturbances from the TP. Finally, we obtain similar results from model simulations; that is, above-normal snow over the TP in May will result in above-normal summer rainfall over the Yangtze and Yellow River basins. But we still can find that model simulation results do not strictly match data analysis in each aspect; the uncertainties of snow datasets, model bias, and simulation design are potential causes. Thus more detailed analysis still needs to be carried out in the future.

Previous studies (Chen et al. 2000; Zhang and Tao 2001; Wu and Qian 2003) have argued that excessive TP snow cover may weaken the EASM. We find a similar result, using the EASM index suggested by Wang et al. (2008), with a correlation coefficient of -0.58 (significant at the $99 \%$ confidence level) between SCAP and the EASM index (Fig. S3 in the supplementary material). While the seasonal transition over East Asia shows little difference between above- and below-normal TP snow cover years (Fig. S4 in the supplementary material), the different influences of TP snow cover on EASM strength and seasonal transition need to be studied further. The main summer rainband in East Asia shows a large meridional excursion (Tao and Chen 1987;

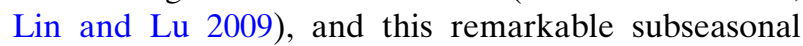
meridional shift should be considered. The characteristics of the rainfall may be different in each month. Thus, in the future, it would be better to study the relationship between the monthly summer precipitation in East Asia and TP snow cover. One of the most important reasons why we focus only on the Yangtze and Yellow River basins in this study is that there is a persistent positive correlation between precipitation and TP snow cover across the basin from June to August (Fig. S5 in the supplementary material), while the signals in other parts of East Asia are discontinuous during this period. Considering the enhanced ENSO-EASM relationship within the past 50 years ( $\mathrm{Li}$ et al. 2010), the ENSO effect must also receive more attention in future work, rather than being removed.

Acknowledgments. This work was jointly supported by the National Natural Science Foundation of China (Grants 91337216, 41175070, and 41605038), and the Special Fund for Public Welfare Industry (meteorology) administered by the Chinese Ministry of Finance and the Ministry of Science and Technology (Grant GYHY201406001).

\section{REFERENCES}

Adler, R. F., and Coauthors, 2003: The version-2 Global Precipitation Climatology Project (GPCP) monthly precipitation analysis (1979-present). J. Hydrometeor., 4, 1147-1167, doi:10.1175/1525-7541(2003)004<1147:TVGPCP>2.0.CO;2.

Armstrong, R. L., M. J. Brodzik, K. Knowles, and M. Savoie, 2005: Global monthly EASE-Grid snow water equivalent climatology. NASA National Snow and Ice Data Center Distributed Active Archive Center, doi:10.5067/KJVERY3MIBPS.

Bamzai, A. S., and J. Shukla, 1999: Relation between Eurasian snow cover, snow depth, and the Indian summer monsoon: An observational study. J. Climate, 12, 3117-3132, doi:10.1175/ 1520-0442(1999)012<3117:RBESCS > 2.0.CO;2.

Barnett, T. P., L. Dümenil, U. Schlese, and E. Roeckner, 1988: The effect of Eurasian snow cover on global climate. Science, $\mathbf{2 3 9}$, 504-507, doi:10.1126/science.239.4839.504.

$-, \ldots, \ldots, \ldots$, and M. Latif, 1989: The effect of Eurasian snow cover on regional and global climate variations. J. Atmos. Sci., 46, 661-685, doi:10.1175/1520-0469(1989)046<0661: TEOESC $>2.0 . \mathrm{CO} ; 2$.

Bayard, D., M. Stähli, A. Parriaux, and H. Flühler, 2005: The influence of seasonally frozen soil on the snowmelt runoff at two Alpine sites in southern Switzerland. J. Hydrol., 309, 66-84, doi:10.1016/j.jhydrol.2004.11.012.

Blanford, H. F., 1884: On the connexion of the Himalayan snowfall with dry winds and seasons of drought in India. Proc. Roy. Soc. London, 37, 3-22, doi:10.1098/rspl.1884.0003. 
Chen, L., and Z. Yan, 1979: Impact of Himalayan winter-spring snow cover on atmospheric circulation and on southern Chinese rainfall in the rainy season (in Chinese). Collected Papers on Medium- and Long-Term Hydrologic and Meteorological Forecasts, Water Conservancy and Power Press, 185-194.

- , and R. Wu, 2000: Interannual and decadal variations of snow cover over Qinghai-Xizang Plateau and their relationships to summer monsoon rainfall in China. Adv. Atmos. Sci., 17, 18-30, doi:10.1007/s00376-000-0040-7.

Chen, Q., B. Gao, and Q. Zhang, 2000: Winter Qinghai-Xizang Plateau snow cover anomalies and summer monsoon variability and their interrelated physics diagnosis (in Chinese). Chin. J. Atmos. Sci., 24, 477-492.

Cohen, J., and D. Rind, 1991: The effect of snow cover on the climate. J. Climate, 4, 689-706, doi:10.1175/1520-0442(1991)004<0689: TEOSCO $>2.0 . \mathrm{CO} ; 2$.

Dai, L. Y., and T. Che, 2010: Cross-platform calibration of SMMR, SMM/I and AMSR-E passive microwave brightness temperature. Sixth International Symposium on Digital Earth: Data Procession and Applications, H. D. Guo and C. L. Wang, Eds., International Society for Optical Engineering (SPIE Proceedings, Vol. 7841), 784103, doi:10.1117/12.873150.

Dee, D. P., and Coauthors, 2011: The ERA-Interim reanalysis: Configuration and performance of the data assimilation system. Quart. J. Roy. Meteor. Soc., 137, 553-597, doi:10.1002/qj.828.

Duan, A., and G. Wu, 2008: Weakening trend in the atmospheric heat source over the Tibetan Plateau during recent decades. Part I: Observations. J. Climate, 21, 3149-3164, doi:10.1175/2007JCLI1912.1

—-, M. Wang, and Z. Xiao, 2014: Uncertainties in quantitatively estimating the atmospheric heat source over the Tibetan Plateau. Atmos. Oceanic Sci. Lett., 7, 28-33, doi:10.1080/ 16742834.2014.11447131.

Ebita, A., and Coauthors, 2011: The Japanese 55-Year Reanalysis "JRA-55": An interim report. SOLA, 7, 149-152, doi:10.2151/ sola.2011-038.

Gao, R., Z. G. Wei, and W. J. Dong, 2004: Analysis of the cause of differentia in interannual variation between snow cover and seasonal frozen soil in the Tibetan Plateau (in Chinese). J. Glaciol. Geocryol., 26, 153-159.

Gong, D.-Y., J. Yang, S.-J. Kim, Y. Gao, D. Guo, T. Zhou, and M. Hu, 2011: Spring Arctic Oscillation-East Asian summer monsoon connection through circulation changes over the western North Pacific. Climate Dyn., 37, 2199-2216, doi:10.1007/s00382-011-1041-1.

Hahn, D. G., and J. Shukla, 1976: Apparent relationship between Eurasian snow cover and Indian monsoon rainfall. J. Atmos. Sci., 33, 2461-2462, doi:10.1175/1520-0469(1976)033<2461: AARBES $>2.0 . \mathrm{CO} ; 2$.

Hu, J., and A. M. Duan, 2015: Relative contribution of the Tibetan Plateau thermal forcing and the Indian Ocean sea surface temperature basin mode to the interannual variability of the East Asian summer monsoon. Climate Dyn., 45, 2697-2711, doi:10.1007/s00382-015-2503-7.

Huang, R., W. Chen, B. Yan, and R. Zhang, 2004: Recent advances in studies of the interaction between the East Asian winter and summer monsoons and ENSO cycle. Adv. Atmos. Sci., 21, 407-424, doi:10.1007/BF02915568.

Li, J., Z. Wu, Z. Jiang, and J. He, 2010: Can global warming strengthen the East Asian summer monsoon? J. Climate, 23, 6696-6705, doi:10.1175/2010JCLI3434.1.

Lin, Z., and R. Lu, 2009: The ENSO's effect on eastern China rainfall in the following early summer. Adv. Atmos. Sci., 26 , 333-342, doi:10.1007/s00376-009-0333-4.
Liu, G., R. Wu, Y. Zhang, and S. Nan, 2014a: The summer snow cover anomaly over the Tibetan Plateau and its association with simultaneous precipitation over the meiyu-baiu region. Adv. Atmos. Sci., 31, 755-764, doi:10.1007/s00376-013-3183-z. $\longrightarrow$, and $-2014 \mathrm{~b}$ : Persistence of snow cover anomaly over the Tibetan Plateau and the implications for forecasting summer precipitation over the meiyu-baiu region. Atmos. Ocean. Sci. Lett., 7, 115-119, doi:10.3878/j.issn.1674-2834.13.0074.

Liu, H.-C., and K.-Q. Duan, 2012: Effects of North Atlantic Oscillation on summer precipitation over the Tibetan Plateau (in Chinese). J. Glaciol. Geocryol., 31, 311-318.

Liu, Y., G. Wu, H. Liu, and P. Liu, 2001: Condensation heating of the Asian summer monsoon and the subtropical anticyclone in the Eastern Hemisphere. Climate Dyn., 17, 327-338, doi:10.1007/s003820000117.

Mote, T. L., 2008: On the role of snow cover in depressing air temperature. J. Appl. Meteor. Climatol., 47, 2008-2022, doi:10.1175/2007JAMC1823.1.

Ose, T., 1996: The comparison of the simulated response to the regional snow mass anomalies over Tibet, eastern Europe and Siberia. J. Meteor. Soc. Japan, 74, 845-866.

$\mathrm{Pu}, \mathrm{Z}$., L. Xu, and V. V. Salomonson, 2007: MODIS/Terra observed seasonal variations of snow cover over the Tibetan Plateau. Geophys. Res. Lett., 34, L06706, doi:10.1029/ 2007GL029262.

Qian, W., B. Lu, and H. Liang, 2011: Changes in fossil-fuel carbon emissions in response to interannual and interdecadal temperature variability. Chin. Sci. Bull., 56, 319-324, doi:10.1007/ s11434-010-4279-9.

Qian, Y. F., Y. Q. Zheng, Y. Zhang, and M. Q. Miao, 2003: Responses of China's summer monsoon climate to snow anomaly over the Tibetan Plateau. Int. J. Climatol., 23, 593-613, doi:10.1002/joc. 901.

Qin, D. H., S. Y. Liu, and P. J. Li, 2006: Snow cover distribution, variability, and climate change in western China. J. Climate, 19, 1820-1833, doi:10.1175/JCLI3694.1.

Reynolds, R. W., T. M. Smith, C. Liu, D. B. Chelton, K. S. Casey, and M. G. Schlax, 2007: Daily high-resolution-blended analyses for sea surface temperature. J. Climate, 20, 5473-5496, doi:10.1175/2007JCLI1824.1.

Robock, A., M. Mu, K. Vinnikov, and D. Robinson, 2003: Land surface conditions over Eurasia and Indian summer monsoon rainfall. J. Geophys. Res., 108, 4131, doi:10.1029/2002JD002286.

Rodell, M., and Coauthors, 2004: The Global Land Data Assimilation System. Bull. Amer. Meteor. Soc., 85, 381-394, doi:10.1175/BAMS-85-3-381.

Souma, K., and Y. Wang, 2010: A comparison between the effects of snow albedo and infiltration of melting water of Eurasian snow on East Asian summer monsoon rainfall. J. Geophys. Res., 115, D02115, doi:10.1029/2009JD012189.

Stackhouse, P. W., S. K. Gupta, S. J. Cox, J. C. Mikovitz, T. Zhang, and M. Chiacchio, 2004: 12-year surface radiation budget data set. GEWEX News, Vol. 14, International GEWEX Project Office, Silver Spring, MD, 10-12.

Tao, S.-Y., and Y.-H. Ding, 1981: Observational evidence of the influence of the Qinghai-Xizang (Tibet) Plateau on the occurrence of heavy rain and severe convective storms in China. Bull. Amer. Meteor. Soc., 62, 23-30, doi:10.1175/1520-0477(1981)062<0023: OEOTIO $>2.0 . \mathrm{CO} ; 2$

, and L.-X. Chen, 1987: A review of recent research on the East Asian summer monsoon in China. Monsoon Meteorology, C. P. Chang, and T. N. Krishnamurti, Eds., Oxford University Press, 60-92. 
Ueda, H., M. Shinoda, and H. Kamahori, 2003: Spring northward retreat of Eurasian snow cover relevant to seasonal and interannual variations of atmospheric circulation. Int. J. Climatol., 23, 615-629, doi:10.1002/joc.903.

Walker, G. R., 1910: Correlations in seasonal variations of weather II. Mem. Indian Meteor. Dept., 21, 22-45.

Wang, B., R. Wu, and X. Fu, 2000: Pacific-East Asian teleconnection: How does ENSO affect East Asian climate? $J$. Climate, 13, 1517-1536, doi:10.1175/1520-0442(2000)013<1517: PEATHD $>2.0 . \mathrm{CO} ; 2$.

, Z. Wu, J. Li, J. Liu, C.-P. Chang, Y. Ding, and G. Wu, 2008: How to measure the strength of the East Asian summer monsoon. J. Climate, 21, 4449-4463, doi:10.1175/ 2008JCLI2183.1.

Wang, Z., A. Duan, and G. Wu, 2014a: Time-lagged impact of spring sensible heat over the Tibetan Plateau on the summer rainfall anomaly in East China: Case studies using the WRF model. Climate Dyn., 42, 2885-2898, doi:10.1007/ s00382-013-1800-2.

,-- , and,$- 2014 \mathrm{~b}$ : Impacts of boundary layer parameterization schemes and air-sea coupling on WRF simulation of the East Asian summer monsoon. Sci. China Earth Sci., 57, 1480-1493, doi:10.1007/s11430-013-4801-4.

Wielicki, B. A., B. R. Barkstrom, E. F. Harrison, R. B. Lee, G. L. Smith, and J. E. Cooper, 1996: Clouds and the Earth's Radiant Energy System (CERES): An Earth Observing System experiment. Bull. Amer. Meteor. Soc., 77, 853-868, doi:10.1175/ 1520-0477(1996)077<0853:CATERE > 2.0.CO;2.

Wu, B., R. Zhang, B. Wang, and R. D'Arrigo, 2009: On the association between spring Arctic sea ice concentration and Chinese summer rainfall. Geophys. Res. Lett., 36, L09501, doi:10.1029/2009GL037299.

Wu, H., S. Hai, and L. Huang, 2015: Possible linkage between spring surface sensible heat flux anomalies over the mid-high latitudes of the Eurasian continent and summer precipitation in the middle-lower reaches of the Yangtze River (in Chinese). Climatic Environ. Res., 20, 119-128.

Wu, R., G. Liu, and P. Zhao, 2014: Contrasting Eurasian spring and summer climate anomalies associated with western and eastern Eurasian spring snow cover changes. J. Geophys. Res. Atmos., 119, 7410-7424, doi:10.1002/2014JD021764.

Wu, T. W., and Z. A. Qian, 2003: The relation between the Tibetan winter snow and the Asian summer monsoon and rainfall: An observational investigation. J. Climate, 16, 2038-2051, doi:10.1175/1520-0442(2003)016<2038:TRBTTW>2.0.CO;2.

Wu, Z., B. Wang, J. Li, and F.-F. Jin, 2009: An empirical seasonal prediction mode of the East Asian summer monsoon using ENSO and NAO. J. Geophys. Res., 114, D18120, doi:10.1029/ 2009JD011733.

_ J. Ji, Z. Jiang, J. He, and X. Zhu, 2012a: Possible effects of the North Atlantic Oscillation on the strengthening relationship between the East Asian summer and ENSO. Int. J. Climatol., 32, 794-800, doi:10.1002/joc.2309.

,,--- and T. T. Ma, 2012b: Modulation of the Tibetan Plateau snow cover on the ENSO teleconnections: From the East Asian summer monsoon perspective. J. Climate, 25, 2481-2489, doi:10.1175/JCLI-D-11-00135.1.

Xiao, Z., and A. Duan, 2015: Can the tropical storms originated from the Bay of Bengal impact the precipitation and soil moisture over the Tibetan Plateau? Sci. China Earth Sci., 58, 915-928, doi:10.1007/s11430-014-5028-8.

Xie, P., and P. A. Arkin, 1997: A 17-year monthly analysis based on gauge observations, satellite estimates, and numerical model outputs. Bull. Amer. Meteor. Soc., 78, 2539-2558, doi:10.1175/ 1520-0477(1997)078<2539:GPAYMA>2.0.CO;2.

Xie, S.-P., K. Hu, J. Hafner, H. Tokinaga, Y. Du, G. Huang, and T. Sampe, 2009: Indian Ocean capacitor effect on Indowestern Pacific climate during the summer following El Niño. J. Climate, 22, 730-747, doi:10.1175/2008JCLI2544.1.

$\mathrm{Xu}$, L., and P. Dirmeyer, 2013: Snow-atmosphere coupling strength. Part II: Albedo effect versus hydrological effect. J. Hydrometeor., 14, 404-418, doi:10.1175/JHM-D-11-0103.1.

Xu, X., J. Guo, T. Koike, Y. Liu, X. Shi, F. Zhu, and S. Zhang, 2012: "Downstream effect" of winter snow cover over the eastern Tibetan Plateau on climate anomalies in East Asia. J. Meteor. Soc. Japan, 90C, 113-130, doi:10.2151/jmsj.2012-C08.

Yanai, M., S. Esbensen, and J. H. Chu, 1973: Determination of bulk properties of tropical cloud clusters from large-scale heat and moisture budgets. J. Atmos. Sci., 30, 611-627, doi:10.1175/ 1520-0469(1973)030<0611:DOBPOT $>2.0 . C O ; 2$.

Yang, J., Q. Liu, S.-P. Xie, Z. Liu, and L. Wu, 2007: Impact of the Indian Ocean SST basin mode on the Asian summer monsoon. Geophys. Res. Lett., 34, L02708, doi:10.1029/2006GL028571.

Yasunari, T., and T. Miwa, 2006: Convective cloud systems over the Tibetan Plateau and their impact on meso-scale disturbances in the meiyu/baiu frontal zone-A case study in 1998. J. Meteor. Soc. Japan, 84, 783-803, doi:10.2151/jmsj.84.783.

— A. Kitoh, and T. Tokioka, 1991: Local and remote responses to excessive snow mass over Eurasia appearing in the northern spring and summer climate-A study with the MRI GCM. J. Meteor. Soc. Japan, 69, 473-487.

Yeh, T.-C., R. T. Wetherald, and S. Manabe, 1983: A model study of the short-term climatic and hydrologic effects of sudden snowcover removal. Mon. Wea. Rev., 111, 1013-1024, doi:10.1175/ 1520-0493(1983)111<1013:AMSOTS>2.0.CO;2.

Zhang, S. L., and S. Y. Tao, 2001: Influences of snow cover over the Tibetan Plateau on Asian summer monsoon (in Chinese). Chin. J. Atmos. Sci., 25, 372-390.

Zhang, Y. C., W. B. Rossow, A. A. Lacis, V. Oinas, and M. I. Mishchenko, 2004: Calculation of radiative fluxes from the surface to top of atmosphere based on ISCCP and other global data sets: Refinements of the radiative transfer model and the input data. J. Geophys. Res., 109, D19105, doi:10.1029/2003JD004457.

Zhang, Y. S., T. Li, and B. Wang, 2004: Decadal change of the spring snow depth over the Tibetan Plateau: The associated circulation and influence on the East Asian summer monsoon. J. Climate, 17, 27802793, doi:10.1175/1520-0442(2004)017<2780:DCOTSS > 2.0.CO;2.

Zhao, P., Z. J. Zhou, and J. P. Liu, 2007: Variability of Tibetan spring snow and its associations with the hemispheric extratropical circulation and East Asian summer monsoon rainfall: An observational investigation. J. Climate, 20, 3942-3955, doi:10.1175/JCLI4205.1.

Zhu, Y. X., Y. H. Ding, and H. W. Liu, 2009: Simulation of the influence of winter snow depth over the Tibetan Plateau on summer rainfall in China (in Chinese). Chin. J. Atmos. Sci., 33, 903-915.

Zwiers, F. W., 1993: Simulation of the Asian summer monsoon with CCC GCM-1. J. Climate, 6, 469-486, doi:10.1175/ 1520-0442(1993)006<0469:SOTASM >2.0.CO;2. 